HELENA DE FAZIO AGUIAR

\title{
MODELAGEM MATEMÁTICA E VALIDAÇÃO EXPERIMENTAL DA PASTEURIZAÇÃO DE LEITE PELA AVALIAÇÃO DO HISTÓRICO DE TEMPERATURA E LETALIDADE EM TROCADOR A PLACAS
}

Texto apresentado à Escola

Politécnica da Universidade de São

Paulo para obtenção do Título de

Mestre em Engenharia 
HELENA DE FAZIO AGUIAR

\section{MODELAGEM MATEMÁTICA E VALIDAÇÃO EXPERIMENTAL DA PASTEURIZAÇÃO DE LEITE PELA AVALIAÇÃO DO HISTÓRICO DE TEMPERATURA E LETALIDADE EM TROCADOR A PLACAS}

Texto apresentado à Escola

Politécnica da Universidade de São

Paulo para obtenção do Título de

Mestre em Engenharia

Área de Concentração:

Engenharia Química

Orientador:

Prof. Dr. Jorge Andrey Wilhelms Gut 
FICHA CATALOGRÁFICA

\section{Aguiar, Helena de Fazio}

Modelagem matemática e validação experimental da pasteurização de leite pela avaliação do histórico de temperatura e leta-lidade em trocador a placas / H.F. Aguiar. -- São Paulo, 2009. $64 \mathrm{p}$.

Dissertação (Mestrado) - Escola Politécnica da Universidade de São Paulo. Departamento de Engenharia Química.

1. Leite 2. Pasteurização (Modelagem matemática) 3. Trocadores de calor I. Universidade de São Paulo. Escola Politécnica. Departamento de Engenharia Química II. t. 
Aos meus pais, Vania e Francisco, e aos meus irmãos, Hugo e Ítalo, com grande carinho e admiração. 
"A mente que se abre a uma nova idéía jamais voltará ao seu tamanho original."

(Albert Einstein) 


\section{AGRADECIMENTOS}

Ao bondoso Deus.

Ao meu orientador Prof. Jorge Gut, pela oportunidade, paciência e dedicação.

À Profa . Carmen Tadini, ao Prof. José Luís de Paiva e ao Prof. Roberto Guardani, pelas valiosas sugestões e contribuições durante a elaboração desse trabalho.

Às amigas do laboratório, em ordem crescente de altura, Ana Cristina de Souza, Diana Sanchez, Janaína Mainardi, Nathalia Aliberti e Otilia Carvalho, pelas risadas, festas, conselhos, almoços e carinho. Aos colegas Carola Gutierrez, Viviane Kechichian, Fabrício Resende, Tatiana Tribess, Cynthia Ditchfield e aos funcionários Ivan Nunes, Vanessa Duarte e Maísa Coelho, pelo apoio.

Às amigas Camila Campagnaro, Caroline Martins, Hellen Costenaro, Marina Mennucci e Michele Anze, pela amizade, apoio e estudos frenéticos em grupo.

Aos amigos Eduardo Finelli, Eva Menezes, Flávia Lemos, Lídia Ruppert, Luciana Takahashi, Miguel Galeti e Ricardo de Miguel, que foram muito importantes em minha adaptação a São Paulo e sempre estiveram presentes de alguma forma.

Às amigas Daniele Nunes, Juliana Ferreira, Marília Cleto, Sarita Rossato e Viviane Jardim, pela amizade incondicional.

Aos meu irmãos, Hugo e Ítalo, por todos os momentos de alegria.

Aos meus pais, que estiveram sempre ao meu lado, pelo exemplo e apoio ao longo de minha vida.

A toda minha família, que sempre vibrou e me incentivou com minhas conquistas.

À CNPq pela bolsa concedida.

A todos que me cercaram de atenção e carinho, reforçando com palavras de incentivo nos momentos difíceis deste trajeto, ajudando-me a transpor os obstáculos e, assim, colaborando para a realização deste trabalho. Muito obrigada! 


\section{RESUMO}

O principal objetivo do trabalho foi desenvolver uma ferramenta de simulação, para servir de base para o projeto e dimensionamento de processos contínuos de pasteurização de alimentos líquidos em trocadores de calor a placas, possibilitando minimizar perdas de qualidade sensorial e nutricional, bem como gastos desnecessários com aquecimento e resfriamento, decorrentes do sobreprocessamento, tendo o controle sobre o histórico de temperatura. Foi desenvolvida uma modelagem matemática para o processo contínuo de pasteurização HTST (High Temperature Short Time) de leite em trocador de calor a placas com três seções, para determinação da distribuição de temperatura ao longo do processo e avaliação do impacto sobre o leite. Foram desenvolvidos três modelos e seus resultados confrontados com os dados experimentais, realizados com água e leite. Os três modelos forneceram resultados similares e próximos ao comportamento experimental. $\mathrm{O}$ cálculo de letalidade permitiu detectar sobreprocessamento no processo estudado. Ensaios com indicador enzimático (fosfatase alcalina em tampão fosfato) foram realizados para quantificar o impacto do processo sobre o produto e comparar com a letalidade calculada pelos modelos.

Palavras-chave: Modelagem matemática. Pasteurização. Processamento térmico. Trocador de calor a placas. 


\section{ABSTRACT}

The aim of this work was to develop a simulation tool to be used in the design of continuous pasteurization of liquid foods using plate heat exchangers, enabling to minimize the nutritional and sensorial losses as well as unnecessary costs during heating and cooling, caused by the overprocessing. The control is made by the temperature profile. A mathematical model was developed for continuous milk HTST (High Temperature Short Time) pasteurization with a three section plate heat exchanger to determine the temperature profile and to evaluate the process impact on the product. Three models were tested and the simulation results compared with the experimental data using water and milk. The results of the three models were similar among them and close to the experimental behavior. Calculating the lethality of the process showed it was overprocessing the product. Tests using enzymatic indicator (alkaline phosphatase in phosphate buffer) were held to quantify the impact of the process on the product and compare to the lethality calculated using the models.

Keywords: Mathematical modeling. Pasteurization. Plate heat exchanger. Thermal processing. 


\section{LISTA DE FIGURAS}

Figura 2-1: Esquema do pedestal com placas corrugadas e gaxetas.

.24

Figura 2-2: Esquema mostrando os parâmetros para descrever um trocador de calor: a, b e c. Dois exemplos mostrados em d e e. .25

Figura 3-1: Esquema do processo de pasteurização indicando os pontos de controle. 33

Figura 3-2: Esquema do volume de controle usado para balanço diferencial no canal do trocador de calor.

37

Figura 3-3: Foto do pasteurizador laboratorial FT-43 (Armfield, UK). 42

Figura 3-4: Esquema da configuração das três seções do pasteurizador. .43

Figura 3-5: Foto do pasteurizador identificando as conexões. .45

Figura 3-6: Pasteurizador utilizado e esquema do processo indicando pontos de controle. 46

Figura 4-1: Distribuição de temperatura para os três modelos e valores experimentais. .51

Figura 4-2: Distribuição de temperatura e a letalidade acumulada para os três modelos. .53

Figura 4-3: Distribuição de temperatura e letalidade acumulada para os dados experimentais. .54 
Figura 4-4: Comparação das curvas de atividade residual calculadas pelo Modelo 2 e com os valores experimentais, curva ideal para pasteurização e o valor medido com produto no final do processo, nas temperalturas de $70{ }^{\circ} \mathrm{C}$,

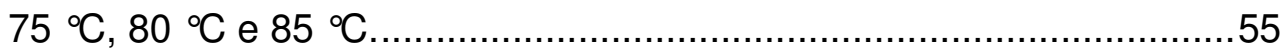

Figura 4-5: Dados de temperatura para processamento contínuo de água destilada e leite integral com $13 \%$ de sólidos totais, sendo temperatura de pasteurização de $72{ }^{\circ} \mathrm{C}$. 


\section{LISTA DE TABELAS}

Tabela 2-1: Valores de temperatura e tempo para pasteurização de leite.

Tabela 3-1: Características das placas do trocador de calor. 44

Tabela 3-2: Principais parâmetros da configuração das três seções do pasteurizador. 44

Tabela 3-3: Identificação e dimensões das conexões utilizadas. .44

Tabela 3-4: Parâmetros cinéticos do indicador enzimático, nas temperaturas processadas.

Tabela 4-1: Balanço de energia com valores experimentais para as três seções do pasteurizador.

Tabela 4-2: Somatória do erro quadrático na determinação das temperaturas, para cada modelo. 52

Tabela 4-3: Valores medidos de atividade enzimática $(A)$ e atividade residual $(A R) \mathrm{e}$ seus desvios padrões, para as temperaturas estudadas .56 


\title{
LISTA DE ABREVIATURAS E SIGLAS
}

\author{
ALP Alkaline Phosphatase \\ FDA Food and Drug Administration \\ HMF Hidroxi-Metil-Furfural \\ HTST High Temperature Short Time \\ TCP Trocador de Calor a Placas \\ PME Pectina Metilesterase \\ TTI Time Temperature Integrator \\ UHT Ultra High Temperature
}




\section{LISTA DE SÍMBOLOS}

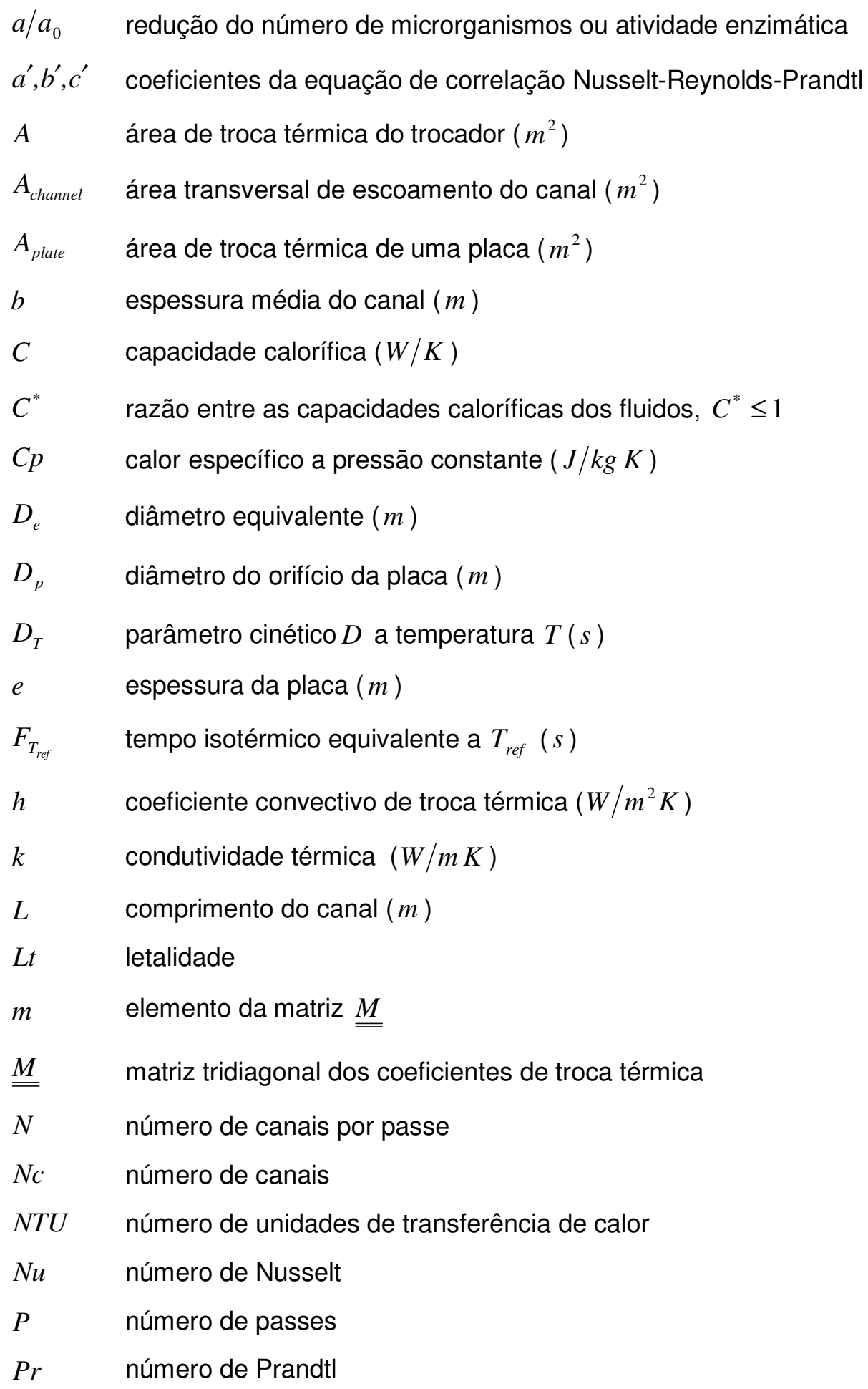




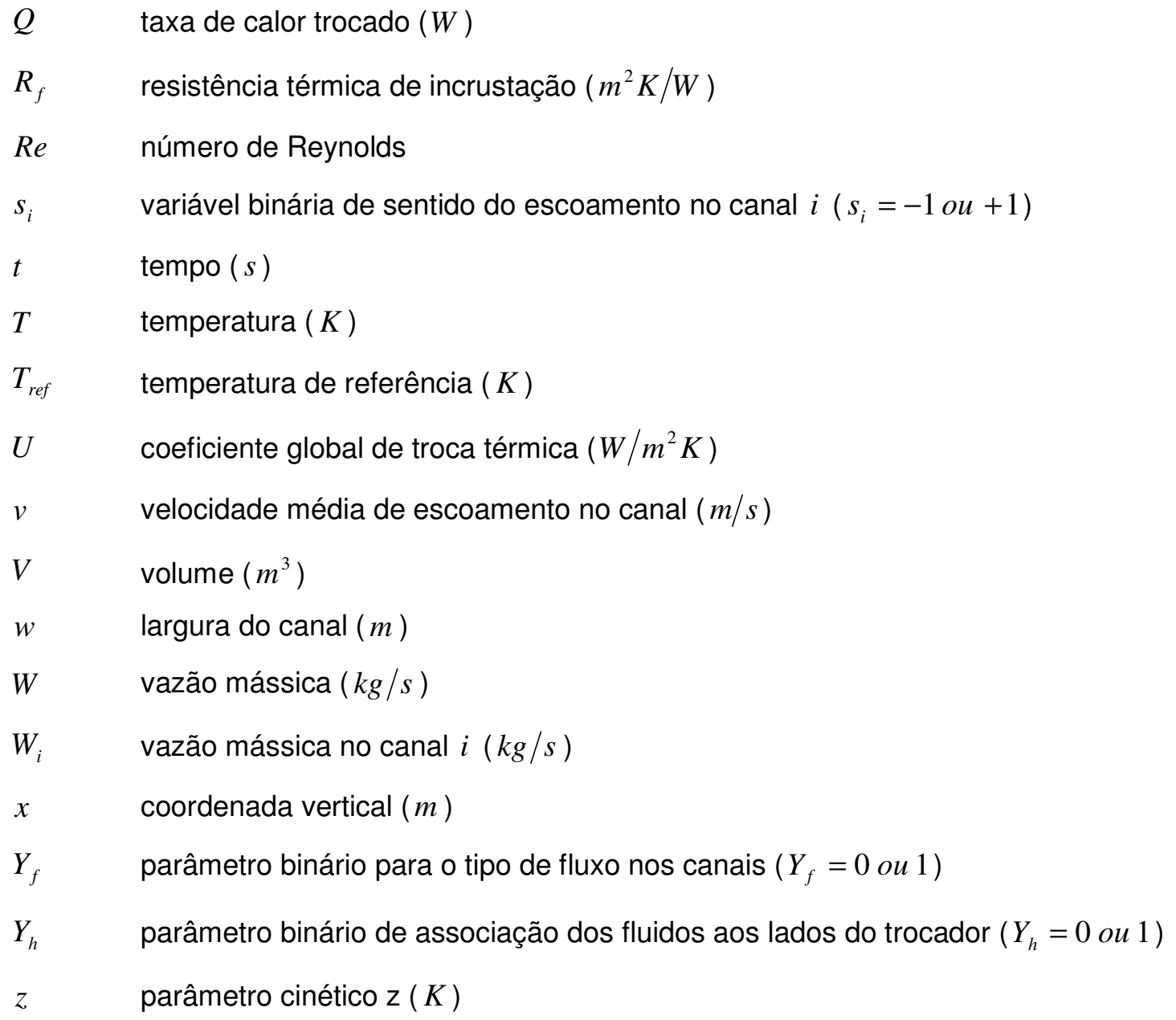

\section{LETRAS GREGAS}

$\alpha \quad$ coeficiente adimensional de troca térmica

$\Delta T_{\text {tube }} \quad$ queda de temperatura no tubo de retenção $(K)$

$\varepsilon \quad$ eficiência de troca térmica (\%)

$\eta \quad$ coordenada vertical adimensional

$\theta, \underline{\theta} \quad$ temperatura adimensional

$\mu \quad$ viscosidade $(P a s)$

$v \quad$ vazão volumétrica $\left(\mathrm{m}^{3} / \mathrm{s}\right)$

$v^{\prime} \quad$ vazão volumétrica $(m L / s)$

$\rho \quad$ densidade $\left(\mathrm{kg} / \mathrm{m}^{3}\right)$ 


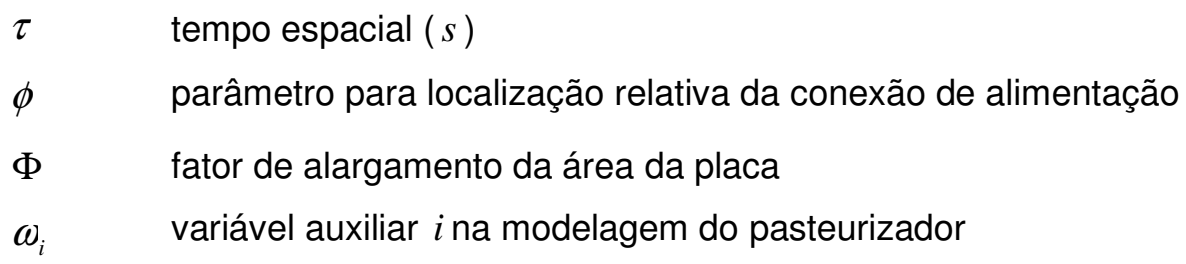

\section{SUBSCRITOS}

$\begin{array}{ll}\text { CC } & \text { escoamento contra-corrente ideal } \\ \exp & \text { experimental } \\ f & \text { incrustação } \\ i & \text { elemento genérico } i \\ \text { in } & \text { entrada } \\ j & \text { elemento genérico } j \\ \text { out } & \text { saída } \\ p, c, h & \text { pontos e passagens na Figura 3-1 } \\ \text { plate } & \text { placa do PHE } \\ \text { tube } & \text { tubo de retenção }\end{array}$

SOBRESCRITOS

$\begin{array}{ll}C & \text { seção de resfriamento do pasteurizador } \\ \text { cold } & \text { fluido frio } \\ H & \text { secão de aquecimento do pasteurizador } \\ \text { hot } & \text { fluido quente } \\ I & \text { lado } I \text { do trocador (conjunto de canais ímpares) } \\ I I & \text { lado } I I \text { do trocador (conjunto de canais pares) } \\ R & \text { seção de regeneração do pasteurizador }\end{array}$




\section{SUMÁRIO}

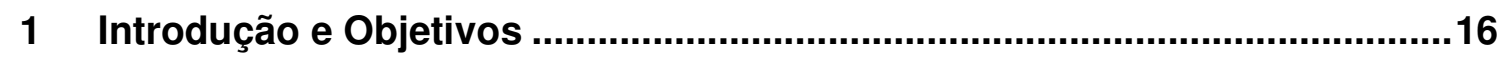

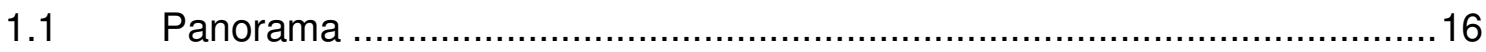

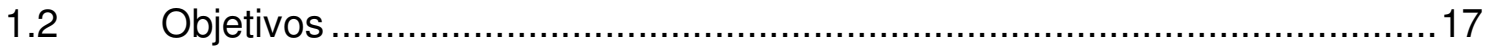

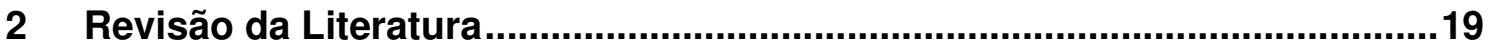

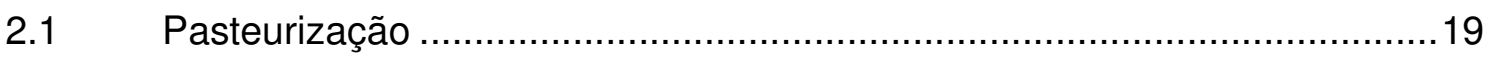

2.2 Estudos do tratamento térmico contínuo em vista da letalidade ................21

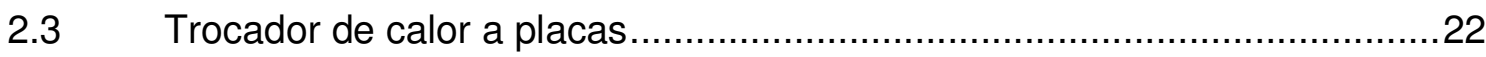

2.4 Cinética de alteração no processo térmico ................................................25

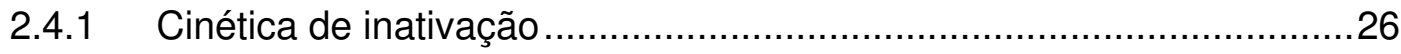

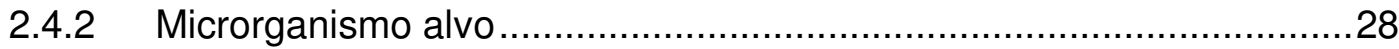

$2.5 \quad$ Uso de integradores tempo-temperatura ...........................................28

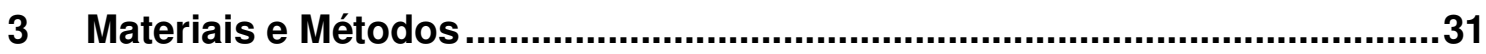

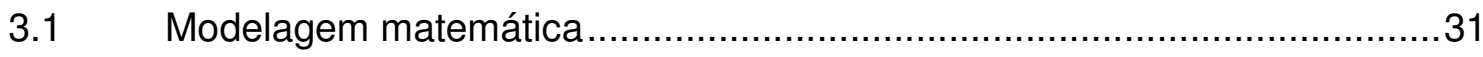

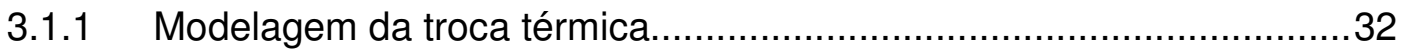

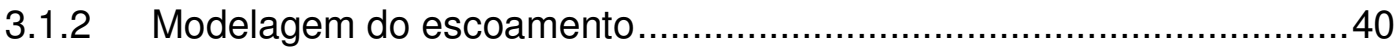

3.1.3 Modelagem do tratamento térmico ………...................................... 41

3.2 Estudo experimental do perfil de temperatura ........................................41

3.3 Validação experimental da letalidade......................................................48

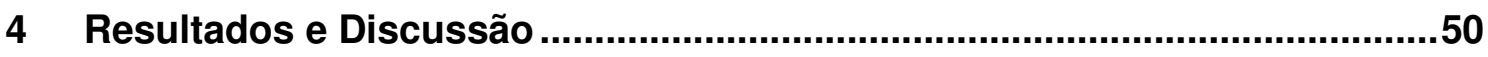

4.1 Avaliação dos modelos e validação térmica ……....................................50

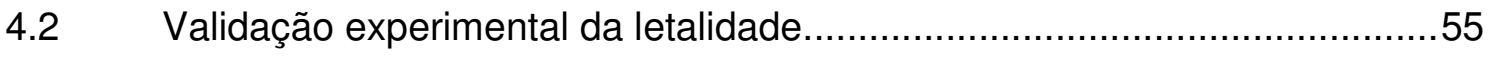

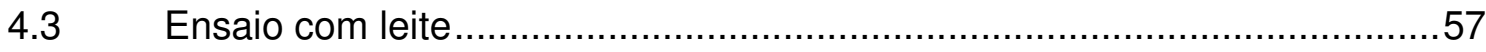




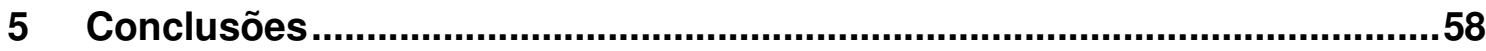

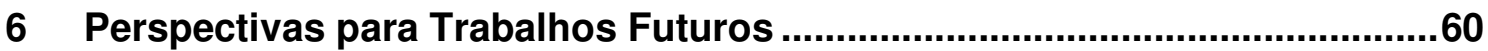

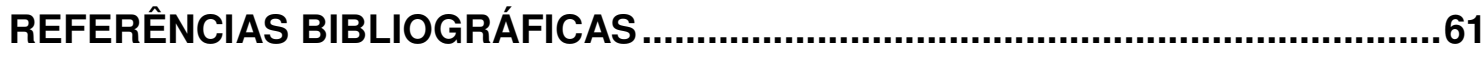




\section{Introdução e Objetivos}

\subsection{Panorama}

Atualmente há uma maior conscientização dos consumidores sobre os benefícios e riscos associados ao consumo de alimentos. Para atingir as expectativas destes consumidores, a indústria de alimentos tem direcionado considerável parte de seus recursos e conhecimentos para a fabricação de produtos seguros e saudáveis. A produção de alimentos seguros inclui a escolha minuciosa dos materiais que entram na cadeia de beneficiamento, interrupção do crescimento microbiano (por exemplo, estocar a temperatura baixa) e a redução ou eliminação da carga microbiana por processamento com posterior prevenção da recontaminação. A presença de uma operação unitária visando à inativação de organismos indesejáveis é de grande importância para garantir a segurança e estabilidade do alimento (LADO; YOUSSEF, 2002).

Tratamentos térmicos são tradicionalmente aplicados para pasteurizar ou esterilizar o alimento, geralmente com perdas de qualidade sensorial e nutricional. Com esta tendência a hábitos mais saudáveis e busca por alimentos minimamente processados que conservam mais características do produto "in natura", a indústria vem procurando otimizar seus processos, assim como adotar tecnologias alternativas (AHVENAINEN, 1996).

Avanços na tecnologia permitem otimizar os processos térmicos à máxima eficiência contra a contaminação e mínima deterioração da qualidade do produto. A pasteurização HTST (High Temperature Short Time) e a esterilização UHT (Ultra High Temperature), por exemplo, minimizam as perdas de vitaminas no leite quando comparados com os processos de pasteurização e esterilização em batelada. Porém, esses processos ainda acarretam em perdas sensoriais e nutricionais (LAVIGNE et al., $1989^{1}$ apud LADO; YOUSSEF, 2002).

\footnotetext{
${ }^{1}$ C. Lavigne, J. A. Zee, R. E. Simard, B. Bellveau, Effect of processing and storage conditions on the fate of vitamins B1, B2, and C and on the shelf-life of goat's milk, J. Food Sci. 54(1989) 30-34.
} 
O processo de pasteurização contínua HTST é destinado ao tratamento térmico de produtos alimentícios líquidos para eliminar as células vegetativas patogênicas. Para aplicação deste processamento térmico em leite, é comum o uso de trocadores de calor a placas, PHE (Plate Heat Exchanger), devido às suas vantagens, como fácil higienização, alta eficiência térmica e viabilidade econômica. Sua função é aquecer o alimento até a temperatura especificada para o processo de pasteurização e resfriá-lo até a temperatura de estoque ou embalagem (KAKAÇ; LIU, 2002).

De acordo com Grijspeerdt et al. (2003), uma modelagem rigorosa do processo é necessária para que se possa simular e otimizar o tratamento térmico que ocorre no pasteurizador, visando determinar condições ótimas de operação, para minimizar os efeitos indesejáveis do aquecimento, garantir a qualidade microbiológica do alimento e reduzir os custos operacionais. Para a correta modelagem, são fundamentais modelos térmico e hidráulico do equipamento e dados confiáveis de cinética de inativação térmica e de propriedades termofísicas.

\subsection{Objetivos}

Os objetivos principais deste trabalho são:

- Desenvolver modelos matemáticos para determinação do histórico de temperatura e avaliação do impacto do processo sobre o produto em uma pasteurização contínua HTST (High Temperature Short Time) em trocador de calor a placas.

- Validar experimentalmente os modelos desenvolvidos, confrontando resultados de simulação e experimentais e selecionando o que melhor descreve o processo.

- Averiguar superdimensionamento do processo nas condições nominais de pasteurização. 
- Verificar se o modelo para determinação de atividade residual da fosfatase alcalina pode ser utilizado na simulação do processo.

- Verificar equivalência térmica entre água e leite no processamento contínuo em trocador de calor a placas no regime permanente. 


\section{Revisão da Literatura}

\subsection{Pasteurização}

Em meados do século XIX, Louis Pasteur criou um método prático de prevenir a deterioração da cerveja e do vinho. Pasteur usou um aquecimento leve, que era suficiente para matar os organismos que causavam o problema de deterioração, sem alterar seriamente o sabor do produto. O mesmo princípio foi aplicado posteriormente ao leite, para produzir o que atualmente denomina-se leite pasteurizado (TORTURA; FUNKE; CASE, 2005).

Como determinado pelo FDA (Food and Drug Administration), na ordem para classe A de leite pasteurizado, revisada em 2003, o termo pasteurização, pasteurizado e termos similares devem significar que o processo de aquecimento de todas as partículas de leite ou produtos de leite, em equipamento corretamente dimensionado e operado, deve ocorrer em uma das temperaturas mostradas na Tabela 2-1 e ser mantido continuamente na mesma temperatura ou acima, por pelo menos o tempo correspondente (USA, 2003).

Tabela 2-1: Valores de temperatura e tempo para pasteurização de leite.

\begin{tabular}{cc}
\hline Temperatura & Tempo \\
\hline $63^{\circ} \mathrm{C}\left(145^{\circ} \mathrm{F}\right)^{*}$ & $30 \mathrm{~min}$ \\
$72^{\circ} \mathrm{C}\left(161^{\circ} \mathrm{F}\right)^{\star}$ & $15 \mathrm{~s}$ \\
$89^{\circ} \mathrm{C}\left(191^{\circ} \mathrm{F}\right)$ & $1,0 \mathrm{~s}$ \\
$90^{\circ} \mathrm{C}\left(194^{\circ} \mathrm{F}\right)$ & $0,5 \mathrm{~s}$ \\
$94^{\circ} \mathrm{C}\left(201^{\circ} \mathrm{F}\right)$ & $0,1 \mathrm{~s}$ \\
$96^{\circ} \mathrm{C}\left(204^{\circ} \mathrm{F}\right)$ & $0,05 \mathrm{~s}$ \\
$100^{\circ} \mathrm{C}\left(21{ }^{\circ} \mathrm{F}\right)$ & $0,01 \mathrm{~s}$ \\
\hline
\end{tabular}

*Se o conteúdo de gordura no produto de leite for dez por cento $(10 \%)$ ou mais, ou contiver adoçantes ou se for concentrado, a temperatura especificada deve ser acrescida de $3{ }^{\circ} \mathrm{C}\left(5^{\circ} \mathrm{F}\right)$.

De acordo com o artigo 517 do Decreto № 30691, de 29 de março de 1952 (BRASIL, 1952), que "Aprova o novo Regulamento da Inspeção Industrial e Sanitária 
de Produtos de Origem Animal", entende-se por pasteurização o emprego conveniente do calor, com o fim de destruir totalmente a flora microbiana patogênica, sem alteração sensível da constituição física e do equilíbrio químico do leite, sem prejuízo dos seus elementos bioquímicos, assim como de suas propriedades organolépticas normais. Um dos processos permitidos de pasteurização é a de curta duração, processo contínuo HTST (High Temperature Short Time), que consiste no aquecimento do leite em camada laminar de $72{ }^{\circ} \mathrm{C}$ a $75^{\circ} \mathrm{C}$ por 15 a 20 segundos, em aparelhagem própria.

O processo de pasteurização contínua HTST destina-se ao tratamento térmico de produtos alimentícios líquidos para a eliminação de células vegetativas de microrganismos patogênicos e microrganismos deterioradores e enzimas indesejáveis. A pasteurização busca garantir a segurança microbiológica do alimento e aumentar sua vida de prateleira, preservando as características sensoriais e o valor nutricional (LEWIS; HEPPELL, 2000). Além de matar os patógenos, a pasteurização HTST diminui as contagens bacterianas totais e dessa forma, o leite se conserva bem sob refrigeração.

Em comparação com a esterilização total, a pasteurização é um tratamento térmico leve em que há o compromisso entre segurança e qualidade do produto final. Quando um tratamento mais severo é desejado, para prolongar a vida de prateleira ou inativar esporos termorresistentes, opta-se pelo processo de esterilização UHT (Ultra High Temperature). Este processo, também conhecido como "esterilização comercial", não elimina completamente os microrganismos do produto. Porém, os que sobrevivem dificilmente se desenvolvem nas condições de armazenamento do produto. Esse tratamento é muito útil em partes do mundo onde as condições para refrigeração nem sempre estão disponíveis (TORTORA; FUNKE; CASE, 2005).

Assim como os sucos de frutas, o leite integra uma classe de alimentos em que a aparência natural e fresca é necessária, sendo este, provavelmente, um dos alimentos mais estudados sob esse ponto de vista e grande importância é atribuída na preservação de seu valor nutricional (RICHARDSON, 2001). 


\subsection{Estudos do tratamento térmico contínuo em vista da letalidade}

Processos térmicos envolvem três etapas distintas: aquecimento, permanência (retenção) e resfriamento. Idealmente, consideram-se aquecimento e resfriamento instantâneos e retenção isotérmica. Na prática, todos os três períodos contribuem para que as alterações térmicas ocorram, embora em muitos casos aquecimento e resfriamento se dão de maneira rápida e o período de retenção se torna o de maior importância. Dessa forma, procedimentos são necessários para avaliar cada período individualmente para determinar o efeito completo. O período de retenção é o mais simples de ser tratado, pois normalmente ocorre a temperatura constante e uniforme. Então, é necessário estabelecer como as alterações térmicas são afetadas pelas variações de temperatura durante aquecimento e resfriamento (BRENNAN, 2006).

Para o dimensionamento de processos de pasteurização, normalmente são utilizadas hipóteses simplificadoras que resultam em superdimensionamento e, consequentemente, em sobreprocessamento do produto, acarretando na perda da qualidade do mesmo e também em elevação de custos operacionais, como pôde ser verificado por diversos pesquisadores (JUNG; FRYER, 1999; LANDFELD et al., 2002; GRIJSPEERDT et al., 2004).

Jung e Fryer (1999) simularam a esterilização de um alimento líquido viscoso não-newtoniano em trocadores de calor duplo-tubo através da modelagem do perfil de velocidades dentro do tubo, do início ao fim do processo. A análise dos resultados mostrou que grande parte da inativação térmica ocorre fora do tubo de retenção e que a margem de segurança utilizada no projeto destes processos

promove significativa perda de qualidade, devido ao sobreprocessamento do produto.

Landfeld et al. (2002) analisaram uma unidade pasteurizadora de gema de ovo e constataram que o tempo de retenção no tubo estava $48 \%$ acima do valor requerido pela regulamentação local para pasteurização da gema, devido ao superdimensionamento. 
Grijspeerdt et al. (2004) analisaram três sistemas de esterilização UHT de leite e verificaram que todos estavam superdimensionados com respeito à inativação bacteriana.

Gut et al. (2004) aplicaram a modelagem matemática para configurações generalizadas de trocadores de calor a placas, para determinar a distribuição de temperatura em um pasteurizador a placas, usado para o processamento HTST de leite. Neste exemplo de aplicação para um trocador com 124 canais, sem validação experimental e assumindo escoamento pistonado, verificou-se um considerável sobreprocessamento do leite devido à distribuição de temperatura dentro do trocador (que colaborou com $25 \%$ da letalidade total, $L t$ ) e devido às condições não isotérmicas do tubo de retenção (foi assumido queda linear de temperatura de $2{ }^{\circ} \mathrm{C}$ ).

A simulação para a pasteurização contínua de gema de ovo líquida (escoamento não-newtoniano), apresentada por Gut et al. (2005), em um trocador com 58 canais, também mostrou sobreprocessamento do produto. Foram testados três tipos de modelos matemáticos, mas sem validação experimental, o que poderia indicar se algum deles fornece uma boa predição do processo real. Em todos os casos foi assumido escoamento pistonado com perfil achatado de velocidade.

\subsection{Trocador de calor a placas}

Trocadores de calor a placas têm sido utilizados por muitos anos e estão bem estabelecidos em processos térmicos contínuos, tais como pasteurização e processos UHT para leite, creme, mistura de sorvete, sucos de frutas entre outros (LEWIS; HEPPELL, 2000).

Nos processos de pasteurização HTST de leite, é comum o uso de trocadores de calor a placas para o aquecimento e o resfriamento indireto. Este tipo de trocador oferece grandes vantagens como fácil higiene interna, alta eficiência térmica, turbulência induzida no escoamento a baixa velocidade, viabilidade econômica para fabricação em aço inoxidável, boa distribuição de temperatura e construção compacta e modular que permite acomodar várias seções de troca térmica em um mesmo pedestal (KAKAÇ; LIU, 2002; LEWIS; HEPPELL, 2000). 
A função do trocador de calor é aquecer o alimento até a temperatura de pasteurização especificada para o processo e resfriá-lo até a temperatura de estoque ou embalagem. Para fazer isso de forma eficiente, a entalpia do produto quente é recuperada no pré-aquecimento do produto cru em uma seção de regeneração térmica.

Quando o leite é aquecido, ocorre a formação de um depósito de sólidos na superfície do trocador de calor. Embora não seja suficiente para afetar significativamente a composição do leite, a incrustação resulta em perturbações hidráulicas e térmicas, sendo necessárias operações de limpeza, a fim de que a superfície de troca térmica retorne ao estado inicial (GEORDIADIS, 1998).

Nos processos de produção de leite, a incrustação é um problema que deve ser levado em consideração, pois resulta na redução da capacidade global de troca de calor na seção de aquecimento e leva um aumento no custo de operação (CHENG; FRIIS, 2007).

O trocador de calor a placas ou PHE (Plate Heat Exchanger) consiste basicamente de placas finas de metal retangulares seladas nas bordas por gaxetas e unidas em um mesmo pedestal como mostra a Figura 2-1.

As gaxetas separam cada par de placas para formar canais de escoamento nos quais os fluidos quente e frio circulam alternadamente, trocando calor através das placas metálicas.

Como o equipamento faz uso extensivo de gaxetas, há limitações de pressão e temperatura de operação. Outra importante desvantagem é a alta perda de carga devido aos estreitos canais corrugados por onde os fluidos escoam. Entretanto, a turbulência gerada provoca melhora significativa dos coeficientes convectivos.

O trocador de calor a placas possibilita diferentes configurações, levando em conta o número de canais de escoamento e a distribuição dos fluidos quente e frio. Uma corrente pode seguir sequencialmente pelos canais, realizando diversos passes no trocador (arranjo em série), ou pode ser dividida entre eles, para realizar apenas um passe pelo trocador (arranjo em paralelo). Além dos arranjos, há a possibilidade de combinações entre escoamento série/paralelo que tornam o equipamento muito versátil. A distribuição das correntes ao longo do trocador é determinada pelos tipos e posições de gaxetas usadas, pela perfuração das placas e pela localização dos bocais de alimentação dos fluidos. 


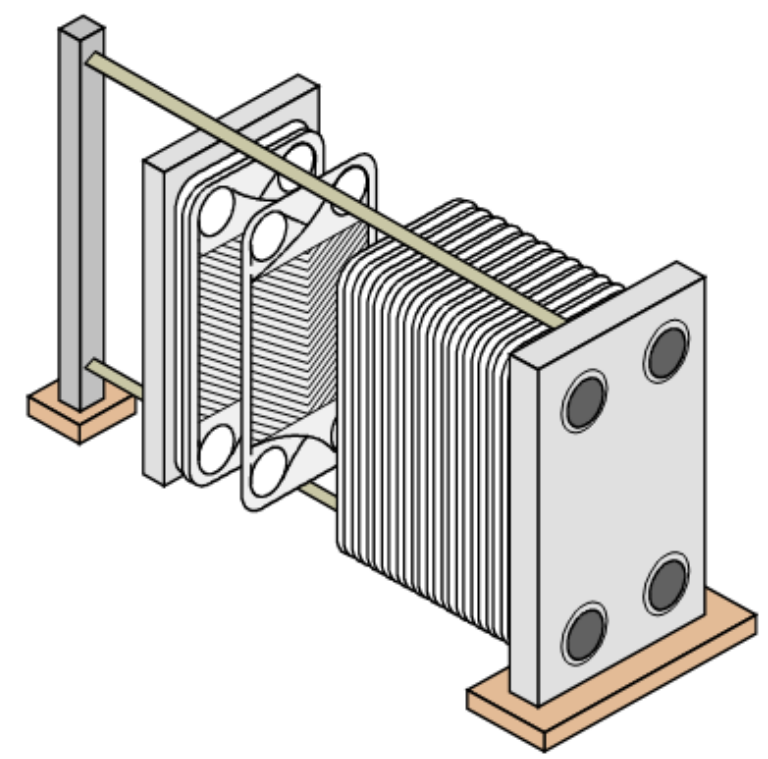

Figura 2-1: Esquema do pedestal com placas corrugadas e gaxetas.

Para se caracterizar a configuração de um PHE, são usados seis parâmetros: $N c$, número de canais; $P^{I}$, número de passes do lado I, que contém os canais ímpares; $P^{I I}$, números de passes do lado II, que contém os canais pares; $\phi$ determina a localização relativa entre conexões de alimentação; $Y_{h}$, parâmetro que descreve por qual lado o fluido quente escoa, sendo seu valor igual a um $\left(Y_{h}=1\right)$, quando o fluido quente escoa através dos canais do lado I e zero $\left(Y_{h}=0\right)$, caso contrário; $Y_{f}$ é o parâmetro que descreve como o fluido escoa dentro de cada canal, $Y_{f}=1$ se o fluido escoa diagonalmente no canal e $Y_{f}=0$, se o escoamento é vertical. Os seis parâmetros são mostrados na Figura 2-2, que apresenta também dois exemplos de configuração de um PHE (GUT, 2003). 

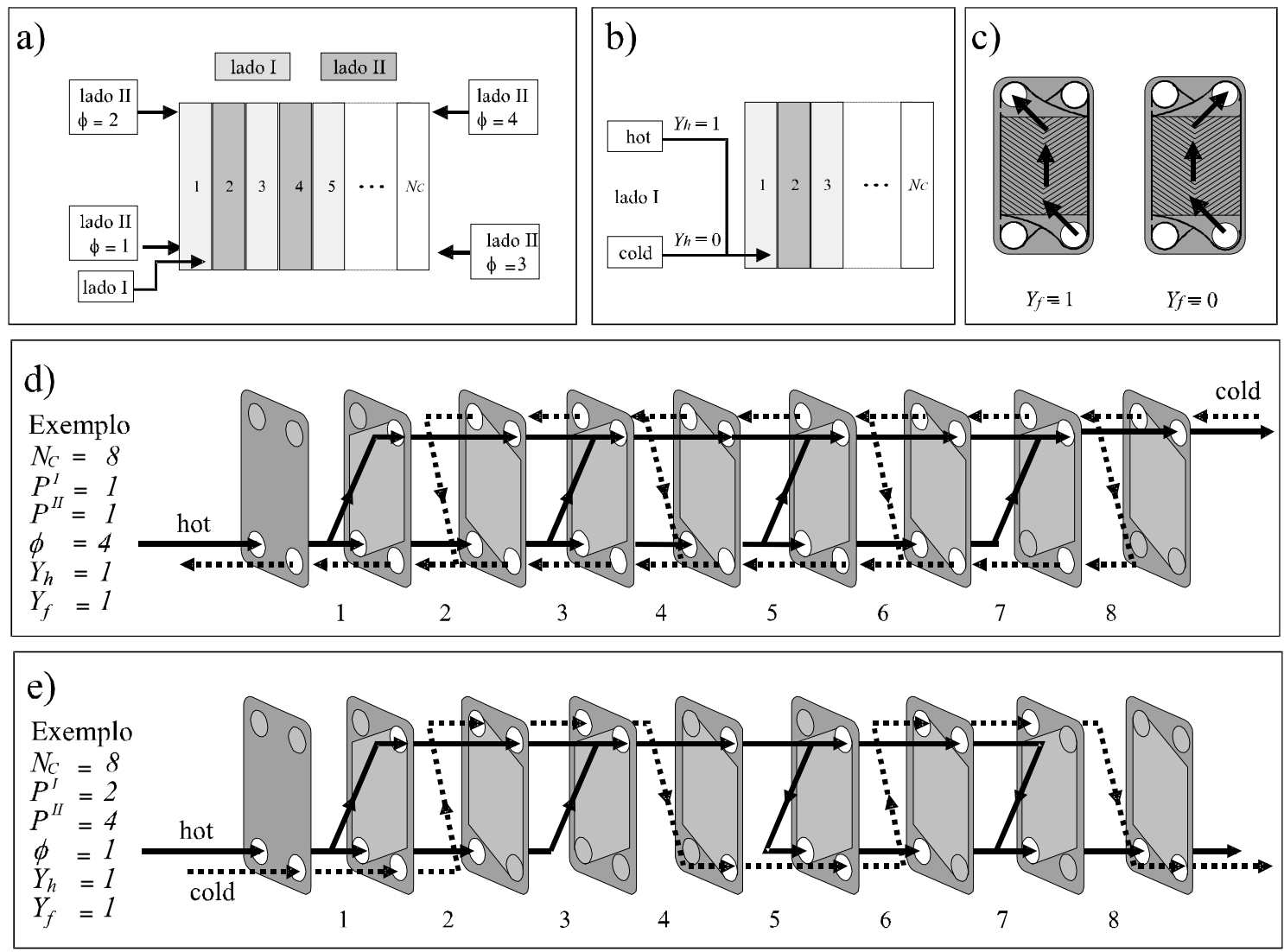

Figura 2-2: Esquema mostrando os parâmetros para descrever um trocador de calor: $a, b$ e c. Dois exemplos mostrados em d e e.

\subsection{Cinética de alteração no processo térmico}

A taxa de mortalidade de microrganismos a altas temperaturas é de grande importância no estudo de processos térmicos de fluxo contínuo. Os diversos microrganismos têm, inerentemente, diferentes resistências a elevadas temperaturas, sendo as células vegetativas e as leveduras geralmente mais suscetíveis, enquanto que esporos mais resistentes e entre esses extremos, encontram-se os vírus (LEWIS; HEPPELL, 2000).

Além da redução da carga microbiana, o tratamento térmico em alimentos pode acarretar em indesejáveis consequências, como perdas nutricionais ou mudanças sensoriais. Essas mudanças físicas ou químicas causadas pela temperatura elevada podem ser reversíveis ou irreversíveis. 
Na pasteurização HTST de leite, não há mudança de sabor significativa, pois pouca ou quase nenhuma proteína do soro é desnaturada e a aglutinação fria e as propriedades bacteriostáticas permanecem virtualmente intactas. No entanto, uma das desvantagens desse tipo de processamento é a degradação parcial de algumas vitaminas, tais como $B_{1}, B_{6}, B_{9}, B_{12}$ e $C$, que apresentam uma perda percentual de 5 a $20 \%$. (WALSTRA et al., 1999).

\subsubsection{Cinética de inativação}

A destruição de microrganismos a elevadas temperaturas é geralmente aceita como uma reação de primeira ordem, isto é, a uma temperatura constante, a taxa de morte do organismo é diretamente proporcional a sua concentração instantânea (LEWIS; HEPPELL, 2000).

De um modo geral, uma equação de cinética de primeira ordem é usada para desnaturação de proteínas, inativação de enzimas e eliminação de bactérias e esporos (WALSTRA et al., 1999).

Os parâmetros do tratamento térmico são $D_{T} \mathrm{e} z$. O tempo de redução decimal, $D_{T}$, pode ser definido como o tempo de tratamento necessário para reduzir o número de microrganismos em um décimo, a uma dada temperatura $T$, ou seja, sua população sofre redução de $90 \%$. Nos cálculos para tratamento térmico é assumido que este valor $D_{T}$ seja independente da concentração inicial de organismos, mas dependente da temperatura, tipo de microrganismo e meio de cultura ou alimento onde $\mathrm{o}$ mesmo se desenvolve. $\mathrm{O}$ parâmetro $z$ representa $\mathrm{O}$ quanto $D_{T}$ é dependente da temperatura, indicando a variação de temperatura necessária para ocasionar uma variação de 10 vezes no valor de $D_{T}$.

A redução da população microbiana ou atividade enzimática em um tratamento isotérmico de duração $t$ pode ser expressa pela eq. (2-1), em que $a_{0}$ representa a população inicial e $a$, a instantânea. $O$ efeito da temperatura no parâmetro $D_{T}$ é mostrado na eq. (2-2) (TOLEDO, 1999). 


$$
\begin{aligned}
& \log \left(\frac{a}{a_{0}}\right)=-\frac{t}{D_{T}} \\
& D_{T}=D_{\text {Tref }} 10^{\left(\frac{T_{\text {ref }}-T}{z}\right)}
\end{aligned}
$$

Vários critérios são usados para determinar o nível de tratamento térmico necessário para determinado alimento, isto é, tempos e temperaturas necessários para resultar em um tratamento adequado para o produto. Usualmente, escolhe-se o microrganismo patogênico mais resistente.

Para tratamento térmico sob condições não isotérmicas, é possível determinar um tempo isotérmico equivalente a uma dada temperatura de referência que gere um mesmo efeito letal, sobre determinada característica, tal qual o tratamento não isotérmico. A letalidade integrada, $F_{T}$, que pode ser calculada usando a eq. (2-3), pode ser considerada como o tempo de retenção a uma temperatura de referência arbitrária (assumindo aquecimento e resfriamento instantâneos) no qual o processo completo é equivalente, em relação à dada característica (LEWIS; HEPPELL, 2000). $\mathrm{Na}$ eq. (2-3), $T(t)$ é uma função que descreve a variação da temperatura com o tempo, ou seja, o histórico de temperatura do produto.

$F_{\text {Tref }}=\int_{0}^{\infty} L t d t=\int_{0}^{\infty} 10^{\left(\frac{T(t)-T_{\text {ref }}}{z}\right)} d t$

A eq. (2-3) pode ser usada para avaliar o tratamento térmico que ocorre no interior do trocador de calor, durante o aquecimento e resfriamento do produto. Como o tratamento térmico é dimensionado para ocorrer apenas no interior do tubo de retenção, qualquer efeito térmico, durante o aquecimento e resfriamento, pode levar ao sobreprocessamento indesejado.

Conhecendo-se todas as temperaturas de entrada e saída das seções do pasteurizador, é possível estimar a distribuição de temperatura ao longo de todo o processo, através de balanços energéticos. 


\subsubsection{Microrganismo alvo}

A pasteurização é um processo térmico que visa à redução do número de microrganismos patogênicos no leite, se presentes, a um nível que não apresente significante risco de danos à saúde. Dessa forma, para o dimensionamento do processo, seleciona-se o organismo patogênico mais termorresistente e nocivo.

As definições internacionais apontam a necessidade de proteger a saúde pública contra a bactéria Coxiella burnetti, sendo este o microrganismo alvo do tratamento térmico de leite. Porém, as condições de pasteurização de leite são definidas a fim de efetivamente destruir os microrganismos $C$. burnetti e Mycobacterium tuberculosis.

A bactéria $C$. burnetti causa a doença conhecida como febre $Q$, sendo seus sintomas febre abrupta, seguida de mal-estar, anorexia, dores musculares e intensa dor de cabeça (MARTH; STEELE, 2001).

Cerf e Condron (2006) questionam se C. burnetti deve realmente ser 0 patógeno alvo no dimensionamento do processo de pasteurização de leite e produtos do leite, pois como mostra seu estudo, a doença causada pela bactéria é resultado da inalação da $C$. burnetti e algumas vezes por mordidas de artrópodes.

\subsection{Uso de integradores tempo-temperatura}

A avaliação do grau de tratamento térmico do alimento pode ser feita de duas formas: teoricamente, através da análise das distribuições de temperatura versus distribuição de tempo de residência ou experimentalmente, utilizando integradores tempo-temperatura (LEWIS; HEPPELL, 2000).

Um integrador tempo-temperatura (TTI, Time-Temperature Integrator) é um componente termicamente sensível, intrínseco ou extrínseco ao alimento, que permite quantificar o impacto do processo térmico sobre um atributo de segurança ou de qualidade, sem conhecimento do histórico de temperatura. O princípio de ação de um TTI pode ser biológico, químico ou físico. As alterações que o processo 
provoca no TTI devem ser irreversíveis e de dinâmica similar ao atributo que é estudado. No caso do leite bovino, a pasteurização visa à destruição da Coxiella burnetti. Para avaliar a eficiência do processo, seria custoso e demorado realizar contagens microbiológicas, antes e depois do processo. Dessa forma, utiliza-se a enzima fosfatase alcalina como TTI, natural do leite e inativada na pasteurização.

A existência de fosfatase em leite foi reconhecida primeiramente em 1925. Em seguida caracterizada como fosfatase alcalina (ALP, EC 3.1.3.1), quando se tornou de grande interesse, pois essa enzima tem a resistência ao calor um pouco maior que patógenos formadores de esporos. Combinações tempo-temperatura necessárias para inativação térmica da ALP são um pouco mais severas que as utilizadas para destruição da bactéria $M$. tuberculosis, até então o microrganismo alvo na pasteurização de leite, garantindo que o leite fique livre de organismos patogênicos. Essa enzima é rapidamente testada e um procedimento para avaliar a inativação da fosfatase alcalina foi desenvolvido como rotina de controle de qualidade de leite, sendo uma medida da eficiência do processo de pasteurização. (FOX; McSWEENEY, 1998; ANGELINO et al., 1999).

Regulamentações européias exigem que a pasteurização de leite deve apresentar atividade positiva para a enzima lactoperoxidase, natural desse alimento. Isso garante que o produto não sofreu sobreprocessamento térmico, pois essa enzima não é totalmente desnaturada na pasteurização, mas somente a temperaturas mais elevadas (LEWIS; HEPPELL, 2000).

Para o suco de laranja, a perda da qualidade é atribuída à atividade da enzima pectina metilesterase (PME), que é mais resistente que microrganismos deterioradores presentes no alimento e, dessa forma, é geralmente utilizada para determinar a intensidade do processo térmico, durante a pasteurização comercial, sendo sua cinética de inativação estudada por Tribess e Tadini (2006). A análise dos resultados mostrou que a máxima inativação, em suco minimamente processado, varia de acordo com o pH e que um modelo cinético de primeira ordem com dois componentes se ajusta melhor aos dados experimentais de inativação térmica do PME.

Gentry e Roberts (2004) estudaram a cinética de formação de HMF (HidroxiMetil-Furfural) como integrador de tempo-temperatura para dois sistemas contínuos de pasteurização de suco de maçã e concluíram que o HMF pode ser utilizado como um indicador químico prático para alimentos com alta acidez, sendo necessários 
ainda estudos para determinar a dependência da cinética de formação com o pH e a concentração do aminoácido asparagina. 


\section{Materiais e Métodos}

O trabalho foi divido em duas partes principais: modelagem matemática e estudo experimental. Na etapa da modelagem matemática, foram desenvolvidos três modelos para simulação do processo de pasteurização. No estudo experimental, testes foram realizados em um pasteurizador para obtenção da distribuição de temperatura. Além disso, foram realizados testes com enzima fosfatase alcalina para validação da modelagem.

\subsection{Modelagem matemática}

Foram desenvolvidos três modelos para determinação da distribuição de temperatura em processo contínuo de pasteurização com trocador a placas em regime permanente. $O$ primeiro modelo assumiu variações lineares de temperatura ao longo do processo, assim como o segundo modelo. $O$ terceiro simulou a variação não-linear de temperatura nos canais do trocador. As considerações utilizadas para a modelagem foram:

- regime permanente;

- sem perda de calor para o ambiente;

- sem troca térmica na direção do escoamento;

- escoamento pistonado dentro dos canais;

- distribuição uniforme através dos canais;

- perfeita mistura no fim do passe;

- sem mudança de fase. 


\subsubsection{Modelagem da troca térmica}

O primeiro modelo (Modelo 1) assumiu variação linear de temperatura e escoamento pistonado (plug flow) para determinação do histórico de temperatura. Dados de entrada para simulação foram: vazões e temperaturas de alimentação, dimensões do equipamento, propriedades termofísicas médias dos fluidos em cada seção, correlação para determinação do coeficiente de convecção no trocador e queda de temperatura no tubo de retenção (GUT et al., 2004).

A carga térmica para as seções de regeneração, aquecimento e resfriamento $\left(Q^{R}, Q^{H}\right.$ e $Q^{C}$ ) para o trocador de calor a placas foi definida pelas eq. (3-1), (3-2) e (3-3) para operação em regime permanente sem perda de calor ou mudança de fase.

$$
\begin{aligned}
& Q^{R}=C_{p 1-2}\left(T_{p 2}-T_{p 1}\right)=C_{p 5-6}\left(T_{p 5}-T_{p 6}\right)=\varepsilon^{R} \min \left(C_{p 1-2}, C_{p 5-6}\right)\left(T_{p 5}-T_{p 1}\right) \\
& Q^{H}=C_{p 2-3}\left(T_{p 3}-T_{p 2}\right)=C_{h 1-2}\left(T_{h 1}-T_{h 2}\right)=\varepsilon^{H} \min \left(C_{p 2-3}, C_{h 1-2}\right)\left(T_{h 1}-T_{p 2}\right) \\
& Q^{C}=C_{p 6-7}\left(T_{p 6}-T_{p 7}\right)=C_{c 1-2}\left(T_{c 2}-T_{c 1}\right)=\varepsilon^{C} \min \left(C_{p 6-7}, C_{c 1-2}\right)\left(T_{p 6}-T_{c 1}\right)
\end{aligned}
$$

Nessas equações, $C=W C p$ é a capacidade calorífica do fluido ( $W$ é a vazão mássica e $C p$ é o calor específico médio) e $\varepsilon$ é a eficiência térmica definida como $Q / Q^{\max }$, em que $Q^{\max }$ é a carga térmica máxima. Os subscritos das variáveis podem ser identificados na Figura 3-1, por exemplo, $C_{p 1-2}$ denota a capacidade térmica média do produto no trecho $\mathrm{p} 1 \rightarrow \mathrm{p} 2$.

Para resolver o sistema de nove equações definidas pelas eqs. (3-1)-(3-3), foi necessário conhecer a eficiência térmica das três seções $\left(\varepsilon^{R}, \varepsilon^{H}\right.$ e $\left.\varepsilon^{C}\right)$ e a queda de temperatura no tubo de retenção $\left(\Delta T_{t u b e}=T_{p 3^{\prime}}-T_{p 4}\right)$. 


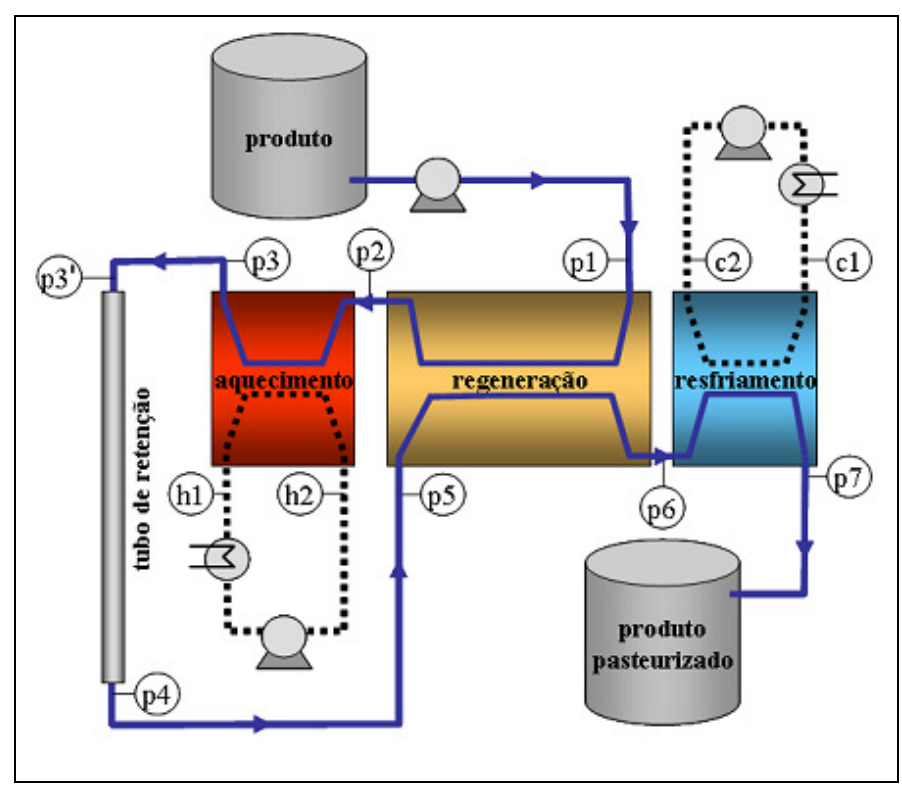

Figura 3-1: Esquema do processo de pasteurização indicando os pontos de controle.

Os valores de eficiência térmica, nas seções do trocador, foram calculados como eficiência de arranjo contracorrente ideal para o Modelo 1. Visto que a eficiência térmica depende da configuração do trocador, assumir eficiência ideal de contracorrente foi a proposta para este primeiro modelo, simplificando amplamente a determinação das temperaturas do processo.

A eficiência térmica para escoamento contracorrente, $\varepsilon_{C C}$, foi calculada pelas eqs. (3-4) e (3-5) em que $N T U$ é o número de unidades de transferência e os subscritos hot e cold identificam os lados quente e frio, respectivamente, do trocador (GUT; PINTO, 2009).

$$
\begin{aligned}
\varepsilon_{c c}= \begin{cases}\frac{1-\exp \left[-N T U\left(1-C^{*}\right)\right]}{1-C^{*} \exp \left[-N T U\left(1-C^{*}\right)\right]} & \text { se } 0<C^{*}<1 \\
\frac{N T U}{N T U+1} & \text { se } C^{*}=1\end{cases} \\
C^{*}=\frac{\min \left(C^{\text {hot }}, C^{\text {cold }}\right)}{\max \left(C^{\text {hot }}, C^{\text {cold }}\right)}
\end{aligned}
$$


O número de unidades de transferência é definido na eq. (3-6) como função do coeficiente global de transferência de calor médio, $U$, e da área de troca térmica $A=\left(N_{C}-1\right) A_{\text {plate }}$. O coeficiente global de troca térmica pôde ser obtido pela eq. (3-7), em que as resistências térmicas entre os fluidos quente e frio levam em conta: convecção $(1 / h)$, condução $\left(e / k_{\text {plate }}\right)$ e incrustação $(R)$.

$$
\begin{aligned}
& N T U=\frac{U A}{\min \left(C^{\text {hot }}, C^{\text {cold }}\right)} \\
& \frac{1}{U}=\frac{1}{h^{\text {hot }}}+\frac{1}{h^{\text {cold }}}+\frac{e}{k_{\text {plate }}}+R^{\text {hot }}+R^{\text {cold }}
\end{aligned}
$$

O coeficiente convectivo $h$ depende principalmente das propriedades do fluido e da velocidade média no canal. Assumindo distribuição uniforme do escoamento entre os canais, a velocidade média no canal foi obtida pela eq. (3-8), em que $A_{\text {channel }}=b w$ é a área transversal média para escoamento no canal, $N$ é o número de canais por passe e $\rho$ é a densidade do fluido.

$$
v=\frac{W}{N \rho A_{\text {channel }}}
$$

Correlações tipo Nusselt-Reynolds-Prandtl são usualmente empregadas para determinação do coeficiente convectivo, $h$. A correlação tem o formato da eq. (3-9). As variáveis adimensionais são: $N u=h D_{e} / k ; \operatorname{Re}=D_{e} v \rho / \mu$ e $\operatorname{Pr}=C p \mu / k$, em que as propriedades termofísicas densidade $\rho$, viscosidade $\mu$, calor específico $C p$ e condutividade térmica $k$ foram estimadas na temperatura média do fluido no trecho; sendo o diâmetro equivalente do canal, $D_{e}$, calculado pela eq. (3-10). 


$$
\begin{aligned}
& N u=a^{\prime} \operatorname{Re}^{b^{\prime}} \operatorname{Pr}^{c^{\prime}} \\
& D_{e}=\frac{2 b}{\Phi}
\end{aligned}
$$

As correlações para determinação das propriedades físicas da água utilizadas neste trabalho são apresentadas nas eqs. (3-11)-(3-14). As propriedades, densidade $\rho\left[\mathrm{kg} / \mathrm{m}^{3}\right]$, viscosidade $\mu[\mathrm{Pas}]$, calor específico $\mathrm{Cp}[\mathrm{J} / \mathrm{kg} \mathrm{K}]$ e condutividade térmica $k[W / K m]$ são calculadas com temperaturas em graus Celsius $T\left[{ }^{\circ} \mathrm{C}\right]$ (GUT; PINTO, 2003).

$$
\begin{aligned}
& \rho=0,208 \times 10^{-4} T^{3}-0,6668 \times 10^{-2} T^{2}+0,04675 T+999,9 \\
& \mu=\frac{1}{21,482\left[(T-8,435)+\sqrt{8078,4+(T-8,435)^{2}}\right]-1200} \\
& C p=0,52013 \times 10^{-6} T^{4}-0,21528 \times 10^{-3} T^{3}+0,041758 T^{2}-2,6171 T+4227,1 \\
& k=0,5692+\frac{T}{538}-\frac{T^{2}}{133333}
\end{aligned}
$$

Para os cálculos das propriedades físicas do leite, as eqs. (3-15), (3-16) e (3-18) foram utilizadas (CHENG; FRIIS, 2007). O calor específico foi calculado pela eq. (3-17), sendo $x_{w}$, a fração de água (CHOI; OKOS, 1986). Estas equações têm as mesmas unidades das eqs. (3-11), (3-12) e (3-14) e também são calculadas com temperaturas em graus Celsius $T\left[{ }^{\circ} \mathrm{C}\right]$, sendo $x_{f}$ a fração de gordura presente no leite.

$$
\begin{aligned}
& \rho=\left(1040,7-0,2665 T-0,0023 T^{2}\right)-x_{f}\left(1,011+0,00976 T-0,481 \times 10^{-4} T^{2}\right) \\
& \mu=\left[\begin{array}{c}
\left(0,9565-0,13004 \times 10^{-2} T+0,1958 \times 10^{-3} T^{2}\right)+ \\
x_{f}\left(0,4766-0,0114 T+0,72642 \times 10^{-4} T^{2}\right)
\end{array}\right] \times 10^{-3}
\end{aligned}
$$




$$
\begin{aligned}
& C p=1675+2512 x_{w} \\
& k=\left(0,528+0,00213 T-0,732 \times 10^{-5} T^{2}\right)\left(1-x_{f}(0,843+0,0019 T)\right)
\end{aligned}
$$

O sistema de equações de (3-1)-(3-3) foi rearranjado para simplificar a determinação das temperaturas do produto $\left(T_{p 2}\right.$ a $T_{p 7}$, indicados pela Figura 3-1) como mostrado pelas eqs. (3-19)-(3-23). Consideram-se $T_{p 3}=T_{p 3^{\prime}}$ e $T_{p 4}=T_{p 5}$, ou seja, conexões adiabáticas.

$$
\begin{aligned}
& T_{p 2}=\frac{\omega_{R 1}\left(\omega_{H} T_{h 1}-\Delta T_{\text {tube }}\right)+\left(1-\omega_{R 1}\right) T_{p 1}}{1-\omega_{R 1}\left(1-\omega_{H}\right)} \\
& T_{p 3}=\omega_{H} T_{h 1}+\left(1-\omega_{H}\right) T_{p 2} \\
& T_{p 5}=T_{p 3}-\Delta T_{\text {tube }} \\
& T_{p 6}=\omega_{R 2} T_{p 1}+\left(1-\omega_{R 2}\right) T_{p 5} \\
& T_{p 7}=\omega_{C} T_{c 1}+\left(1-\omega_{C}\right) T_{p 6}
\end{aligned}
$$

As eqs. (3-24) e (3-25) definem as variáveis auxiliares que dependem das eficiências térmicas das três seções do trocador de calor a placas, $\varepsilon^{R}, \varepsilon^{H}$ e $\varepsilon^{C}$.

$$
\begin{array}{ll}
\omega_{R 1}=\varepsilon^{R} \frac{\min \left(C_{p 1-2}, C_{p 5-6}\right)}{C_{p 1-2}}, & \omega_{R 2}=\varepsilon^{R} \frac{\min \left(C_{p 1-2}, C_{p 5-6}\right)}{C_{p 5-6}} \\
\omega_{H}=\varepsilon^{H} \frac{\min \left(C_{h 1-2}, C_{p 2-3}\right)}{C_{p 2-3}}, & \omega_{C}=\varepsilon^{C} \frac{\min \left(C_{c 1-2}, C_{p 6-7}\right)}{C_{p 6-7}}
\end{array}
$$

Nos Modelos 2 e 3, a eficiência térmica de cada seção foi calculada levando em conta o arranjo real do trocador com escoamento unidimensional conforme Gut e Pinto (2003). No Modelo 2, assim como no Modelo 1, considerou-se variação linear de temperatura entre os pontos de controle. 
O terceiro modelo (Modelo 3) não considerou a variação de temperatura linear e a sua distribuição ao longo das seções do trocador foi determinada pelo balanço diferencial de energia dentro de cada canal, como mostra a Figura 3-2, segundo modelo de trocador a placas de Gut e Pinto (2003).

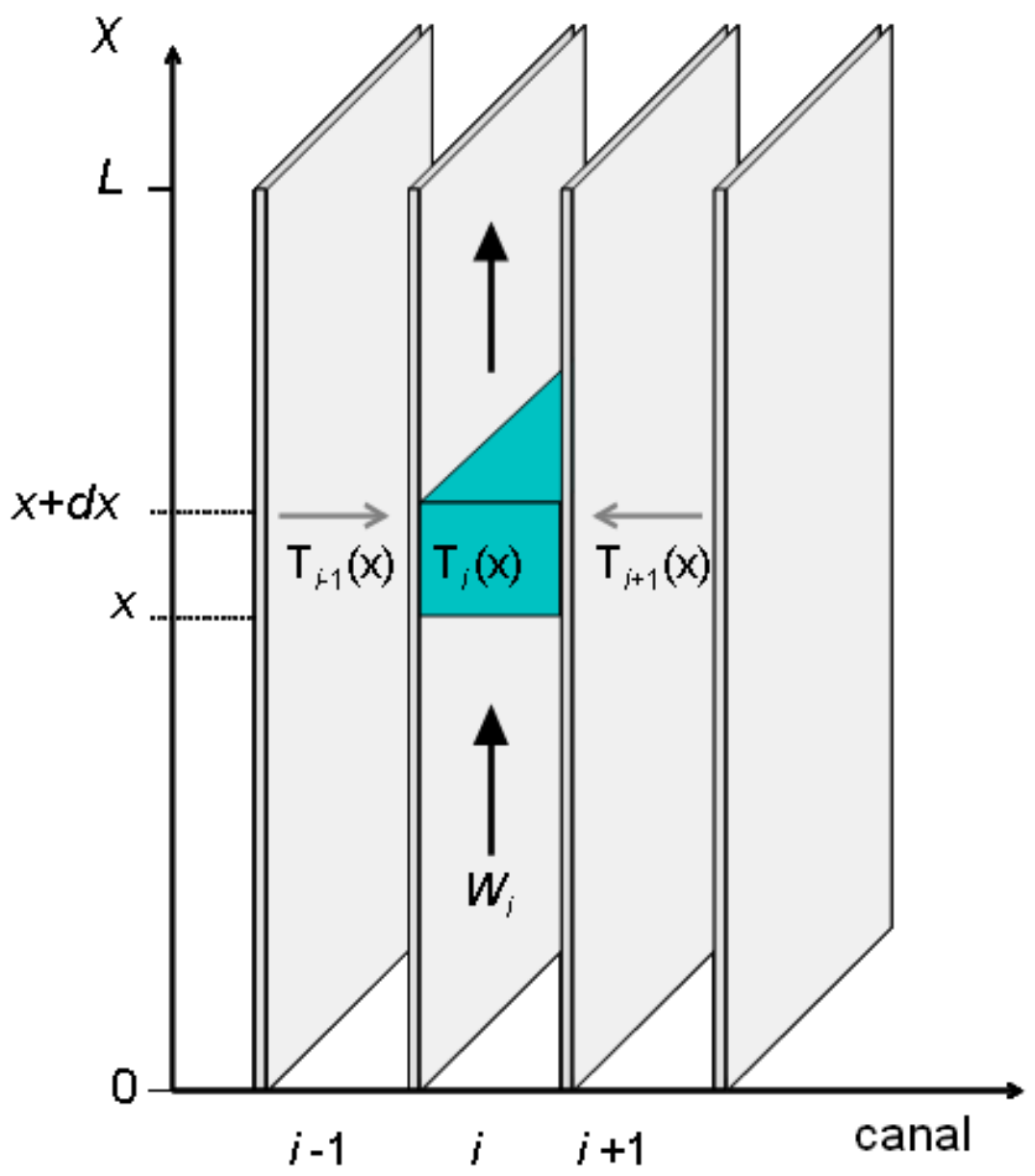

Figura 3-2: Esquema do volume de controle usado para balanço diferencial no canal do trocador de calor.

A variação de temperatura $T$ dentro do canal $i$ de uma seção do trocador a placas é dada pela eq. (3-26), em que $U$ é o coeficiente global de transferência de calor médio, $T_{i}(x)$ é a temperatura no canal $i, W_{i}$ é a vazão mássica no canal $i, C p$ é o calor específico médio e $s_{i}$ é +1 , se o escoamento se dá no sentido de $x$ no canal $i$, ou $s_{i}$ é -1, caso contrário. 
$\frac{d T_{i}}{d x}=\frac{s_{i} w U}{W_{i} C p}\left[\left(T_{i-1}-T_{i}\right)+\left(T_{i+1}-T_{i}\right)\right]$

Utilizando as seguintes variáveis adimensionais, eqs. (3-27) e (3-28):

$$
\begin{aligned}
& \eta(x)=\frac{x}{L} \quad, \quad 0 \leq \eta \leq 1 \\
& \theta_{i}\left(T_{i}\right)=\frac{T_{i}-T_{\text {cold, in }}}{T_{\text {hot }, \text { in }}-T_{\text {cold }, \text { in }}} \quad, \quad 0 \leq \theta \leq 1
\end{aligned}
$$

o balanço energético foi reescrito na forma matricial, como mostram as eqs. (3-29) e (3-30).

$$
\begin{aligned}
& \frac{d \underline{\underline{\theta}}}{d \eta}=\underline{\underline{M}} \cdot \underline{\theta} \\
& \underline{\underline{M}}=\left[\begin{array}{cccccc}
-m_{1} & +m_{1} & 0 & 0 & \ldots & 0 \\
+m_{2} & -2 m_{2} & +m_{2} & 0 & \ldots & 0 \\
0 & +m_{3} & -2 m_{3} & +m_{3} & & \vdots \\
\vdots & & & & & 0 \\
0 & \ldots & 0 & +m_{N c-1} & -2 m_{N c-1} & +m_{N c-1} \\
0 & \ldots & 0 & 0 & +m_{N c} & -m_{N c}
\end{array}\right] \quad \underline{\theta}=\left[\begin{array}{c}
\theta_{1} \\
\theta_{2} \\
\theta_{3} \\
\\
\vdots \\
\theta_{N c}
\end{array}\right]
\end{aligned}
$$

Cada equação do sistema corresponde à conservação de energia em cada canal do trocador de calor. Os coeficientes na matriz $\underline{\underline{M}}$ tridiagonal são $m_{i}=s_{i} \alpha^{I}$, se $i$ é ímpar, ou $m_{i}=s_{i} \alpha^{I I}$, se $i$ é par. O sinal de $m_{i}$ depende da direção do fluxo no canal $i$, de acordo com $s_{i}$. As variáveis $\alpha^{I}$ e $\alpha^{I I}$ são os coeficientes adimensionais de troca térmica para os lados I e II de cada seção do trocador de 
calor e são definidas pela eq. (3-31), assumindo distribuição uniforme da vazão entre canais, $W_{i}=W / N$, em que $N$ é o número de canais por passe.

$$
\alpha^{I}=\frac{A_{\text {plate }} U N^{I}}{C^{I}} \quad \text { e } \quad \alpha^{I I}=\frac{A_{\text {plate }} U N^{I I}}{C^{I I}}
$$

Para resolver a eq. (3-29), condições de contorno foram necessárias para temperatura na entrada de cada canal das três seções do pasteurizador. Para canais com escoamento no sentido positivo do canal, a condição de contorno foi definida na posição $\eta=0,0$. Caso contrário, a condição de contorno foi definida na posição $\eta=1,0$. A temperatura na entrada do canal $i$ foi a de perfeita mistura do fim do passe anterior, como mostrada pela eq. (3-32). As temperaturas de saída dos lados I e II foram definidas da mesma forma, como na eq. (3-33).

$\theta_{i n, i}=\frac{\sum_{j=1}^{N} \theta_{\text {out }, j}}{N} \quad$, onde canais $i$ e $j$ pertencem a passes subsequentes

$\theta_{\text {out }}=\frac{\sum_{j=1}^{N} \theta_{\text {out }, j}}{N} \quad$, onde canais $j$ pertencem ao último passe

A eficiência para cada seção do pasteurizador foi calculada pela eq. (3-34), em função das temperaturas de saída $\theta_{\text {out }}^{I}$ e $\theta_{\text {out }}^{I I}$, determinadas pela resolução da eq. (3-29).

Para todos os três modelos, considerou-se queda linear de temperatura no tubo de retenção, $\Delta T_{\text {tube }}=2{ }^{\circ} \mathrm{C}$. As conexões foram consideradas isotérmicas. 


$$
\mathcal{E}=\left\{\begin{array}{l}
\varepsilon^{I}=\frac{N^{I}}{\alpha^{I}} \max \left(\frac{\alpha^{I}}{N^{I}}, \frac{\alpha^{I I}}{N^{I I}}\right)\left|\theta_{\text {in }}-\theta_{\text {out }}\right|^{I} \\
\varepsilon^{I I}=\frac{N^{I I}}{\alpha^{I I}} \max \left(\frac{\alpha^{I}}{N^{I}}, \frac{\alpha^{I I}}{N^{I I}}\right)\left|\theta_{\text {in }}-\theta_{\text {out }}\right|^{I I}
\end{array}\right.
$$

Foi utilizado o software Excel 2003 (Microsoft, USA) para equacionamento dos Modelo 1 e 2, sendo que a eficiência para este último modelo foi calculada pelo software gPROMS ${ }^{\circledast}$ (Process System Enterprise, Londres, UK), mesmo software usado para simulação do Modelo 3 , em que a dimensão $\eta$ foi discretizada pelo método de diferenças finitas centradas de segunda ordem com 20 elementos.

\subsubsection{Modelagem do escoamento}

Para o correto equacionamento do processo, deve-se usar o valor experimental de tempo médio de residência, $t_{m}$, obtido a partir da curva experimental de distribuição do tempo de residência, DTR.

Com a consideração de escoamento pistonado, plug flow ideal, o tempo de residência médio é igual ao tempo espacial, $\tau$, razão entre o volume interno, $V$, e a vazão volumétrica, $v$, definido pela eq. (3-35) (LEVENSPIEL, 2000).

$\tau=\frac{V}{v}$

Como mencionado anteriormente, supôs-se distribuição uniforme da vazão entre os canais do passe, ou seja, $W_{i}=W / N$. 


\subsubsection{Modelagem do tratamento térmico}

O tratamento térmico do processo foi avaliado pela letalidade integrada e os parâmetros para o equacionamento foram definidos em vista do microrganismo mais termorresistente do produto. O tempo de processo descontínuo e isotérmico, equivalente ao processo não-isotérmico, à temperatura de referência de $\left(T_{r e f}\right), F_{T_{r e f}}$ pôde ser calculado pela eq. (2-3).

$$
F_{T_{r e f}}=\int_{o}^{\infty} L t d t=\int 10^{\frac{T(t)-T_{r e f}}{z}} d t
$$

Assumindo que a temperatura do fluido sofreu variação linear no trocador durante o tempo médio de residência, $t_{m}$, a eq. (2-3) pôde ser simplificada como na eq. (3-36) (GUT; PINTO, 2009). Essa simplificação de linearidade é válida para pasteurizadores a placas com alta eficiência de regeneração (LEWIS; HEPPELL, 2000).

$F_{T_{\text {ref }}}=\frac{z t_{m}}{\left(T_{\text {out }}-T_{\text {in }}\right) \ln (10)}\left[10^{\left(\frac{T_{\text {out }}-T_{\text {ref }}}{z}\right)}-10^{\left(\frac{T_{\text {in }}-T_{\text {ref }}}{z}\right)}\right]$

\subsection{Estudo experimental do perfil de temperatura}

Para a validação experimental dos modelos, foi utilizado um pasteurizador tipo placas FT-43 (Armfield) de laboratório com placas lisas de aço inoxidável, separadas por gaxetas de silicone. A alimentação foi feita por uma bomba 
peristáltica. A Figura 3-3 mostra uma foto do equipamento, na qual podem ser vistas as três seções do trocador, o tanque de alimentação e o tubo de retenção com isolamento térmico.

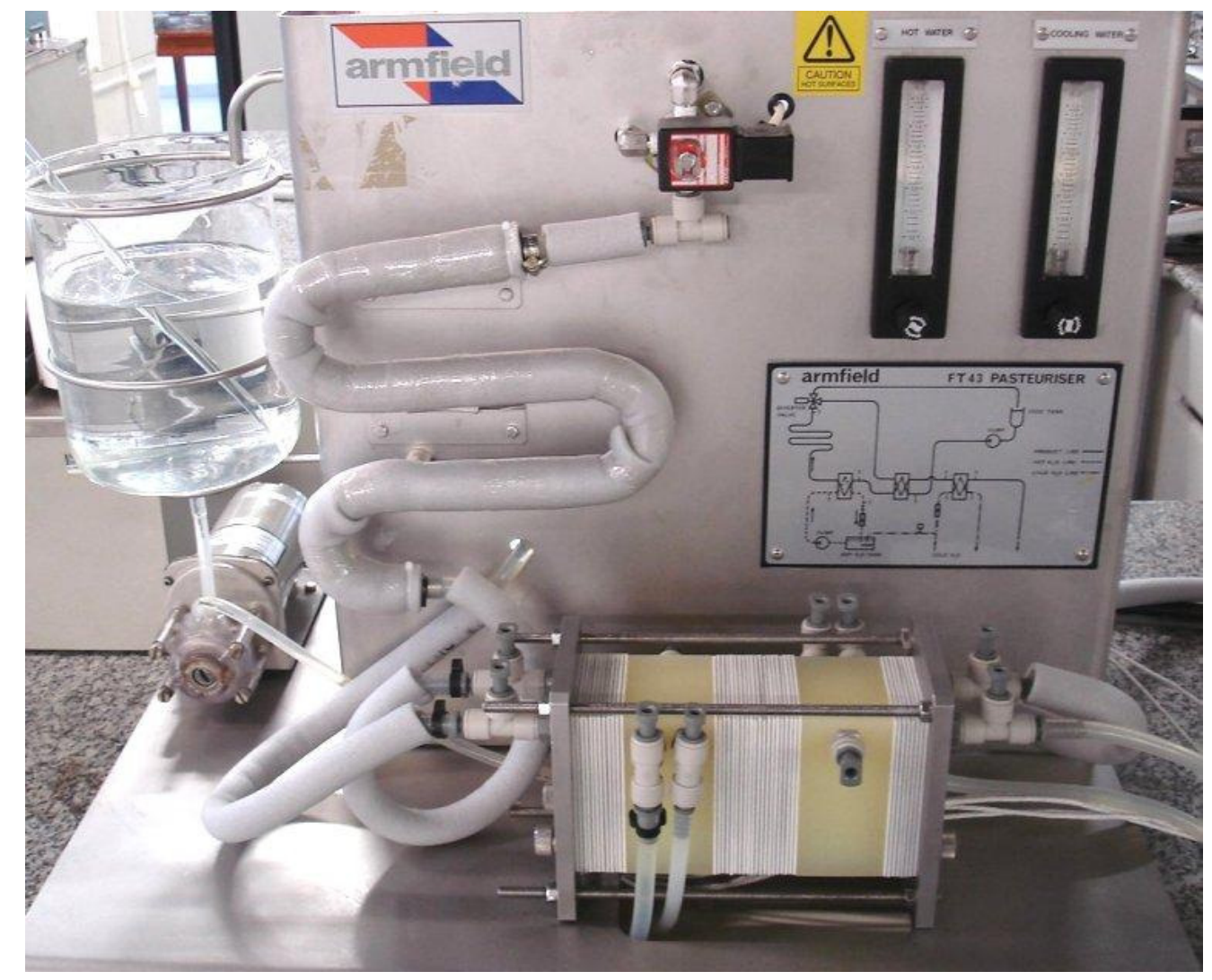

Figura 3-3: Foto do pasteurizador laboratorial FT-43 (Armfield, UK).

As condições nominais deste equipamento para processamento de leite são: vazão igual a $20 \mathrm{~L} / \mathrm{h}$; temperatura de pasteurização de $72{ }^{\circ} \mathrm{C}$; tempo de retenção de $15 \mathrm{~s}$; vazão do aquecimento de $1,0 \mathrm{~L} / \mathrm{min}$ de água a $76{ }^{\circ} \mathrm{C}$; vazão de resfriamento de $1,0 \mathrm{~L} / \mathrm{min}$ de água a $10{ }^{\circ} \mathrm{C}$. A estrutura fundamental do pasteurizador compreende 0 trocador de calor a placas, o qual é dividido em três seções: regeneração, aquecimento e resfriamento, incorporados em um único pedestal; tubo de retenção; circuitos fechados de água de aquecimento e de resfriamento. A temperatura de pasteurização é controlada pela manipulação da carga térmica do circuito fechado de aquecimento. O FT-43 possui uma unidade de controle que permite o 
acompanhamento de seis temperaturas ao longo do processo, com registro online em computador.

O arranjo das três seções foi do tipo série simétrico e contracorrente, conforme Figura 3-4, compreendendo 10 passes de 1 canal na regeneração, 6 passes de 1 canal no aquecimento e 4 passes de 1 canal no resfriamento. As características das placas são apresentadas na Tabela 3-1 e os principais parâmetros da configuração das três seções do pasteurizador na Tabela 3-2.

As dimensões das conexões utilizadas nessa configuração do pasteurizador para ligações entre seções ou entrada e saída do tubo de retenção foram medidas a fim de se conhecer o volume interno e, consequentemente, o tempo espacial. A Tabela 3-3 mostra dimensões e tempo espacial para cada conexão. A Figura 3-5 mostra em destaque as conexões.

O fluido processado foi água destilada. As temperaturas, nos pontos indicados, foram registradas por termopares na operação em regime estacionário, conforme Figura 3-6. Foram utilizados termopares do próprio pasteurizador (Armfield) e também outros adaptados (Instrutherm e lope) para medidas em pontos adicionais.

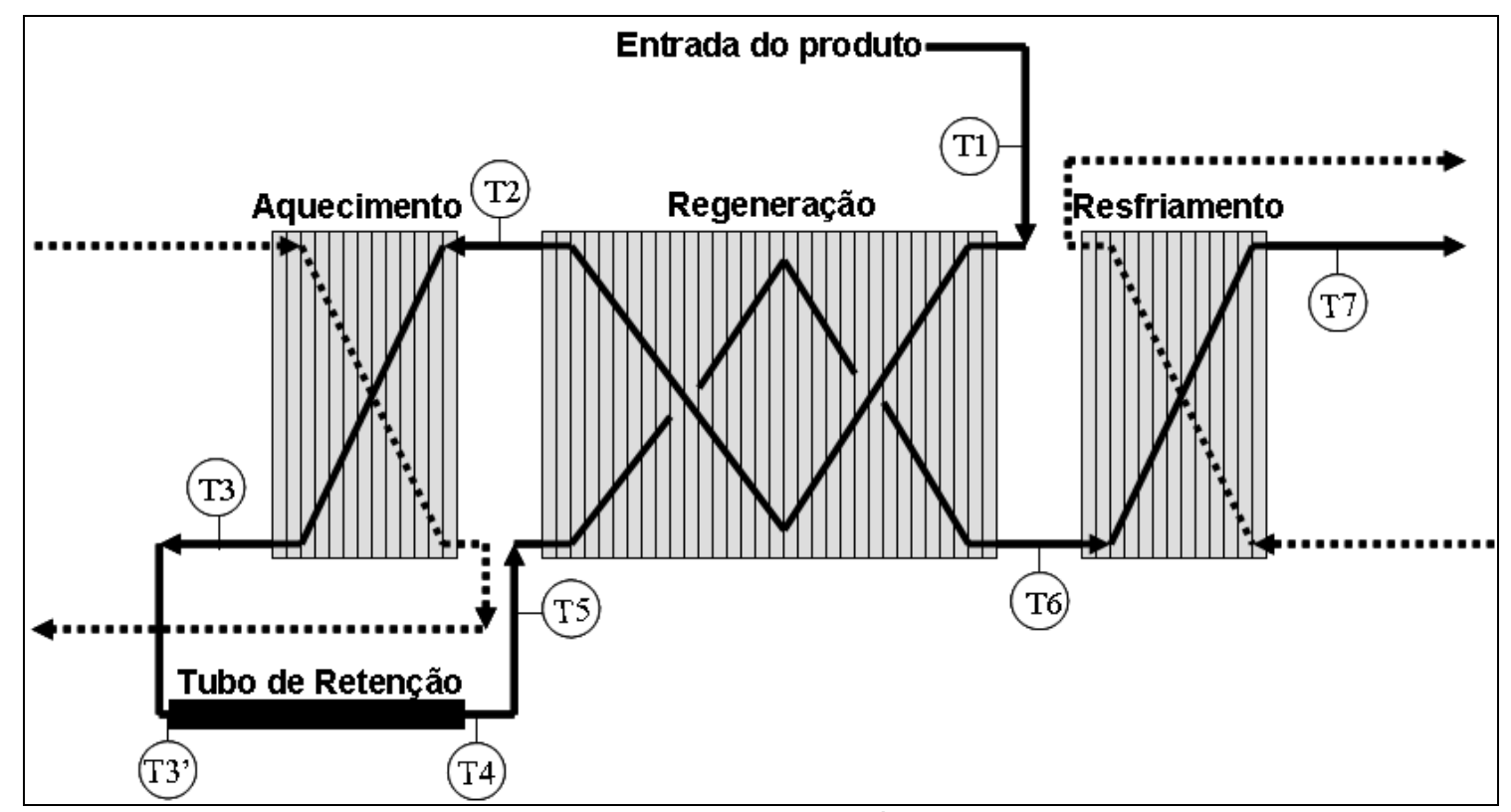

Figura 3-4: Esquema da configuração das três seções do pasteurizador. 
Tabela 3-1: Características das placas do trocador de calor.

\begin{tabular}{lcc}
\hline Comprimento da parte úmida, $L$ & $8,35 \times 10^{-2}$ & $m$ \\
Largura da parte úmida, $w$ & $6,00 \times 10^{-2}$ & $m$ \\
Espessura do canal, $b$ & $1,50 \times 10^{-3}$ & $m$ \\
Diâmetro do orifício, $D p$ & $8,00 \times 10^{-3}$ & $m$ \\
Espessura da placa, $e$ & $1,00 \times 10^{-3}$ & $m$ \\
Fator de alargamento, $\Phi$ & 1,00 & \\
Condutividade térmica, $k$ & $1,34 \times 10^{1}$ & $\mathrm{~W} / \mathrm{Km}$ \\
\hline
\end{tabular}

Tabela 3-2: Principais parâmetros da configuração das três seções do pasteurizador.

\begin{tabular}{lccc}
\hline \multicolumn{1}{c}{ Parâmetros } & $\begin{array}{c}\text { Seção de } \\
\text { Aquecimento }\end{array}$ & $\begin{array}{c}\text { Seção de } \\
\text { Regeneração }\end{array}$ & $\begin{array}{c}\text { Seção de } \\
\text { Resfriamento }\end{array}$ \\
\hline Número de Canais, $N c$ & 12 & 20 & 8 \\
Número de Passes (lado I), $P^{I}$ & 6 & 10 & 4 \\
Número de Passes (lado II), $P^{I I}$ & 6 & 10 & 4 \\
$\begin{array}{l}\text { Posição relativa da conexão de } \\
\text { alimentação do lado II, } \phi\end{array}$ & 3 & 3 & 3 \\
Localização do fluido quente, $Y_{h}$ & 0 & 0 & 1 \\
Tipo de escoamento nos canais, $Y_{f}$ & 1 & 1 & 1 \\
\hline
\end{tabular}

Tabela 3-3: Identificação e dimensões das conexões utilizadas.

\begin{tabular}{|c|c|c|c|c|}
\hline Conexões & & Diâmetro (m) & Comprimento (m) & Tempo espacial (s) \\
\hline $\begin{array}{l}\text { Bloco conector entre trocadores } \\
\text { (material isolante) }\end{array}$ & D & $8,00 \mathrm{E}-03$ & 0,056 & 0,49 \\
\hline Antes do tubo de retenção (isolada) & A & $9,50 \mathrm{E}-03$ & 0,440 & 5,40 \\
\hline Depois do tubo de retenção (isolada) & B & $9,50 \mathrm{E}-03$ & 0,067 & 0,82 \\
\hline $\begin{array}{l}\text { Mangueira longa antes da } \\
\text { regeneração lado II (não isolada) }\end{array}$ & C & $6,00 \mathrm{E}-03$ & 0,860 & 4,21 \\
\hline $\begin{array}{l}\text { Suporte metálico + conexão de } \\
\text { mangueira (não isolado) }\end{array}$ & E & $8,00 \mathrm{E}-03$ & 0,069 & 0,60 \\
\hline
\end{tabular}




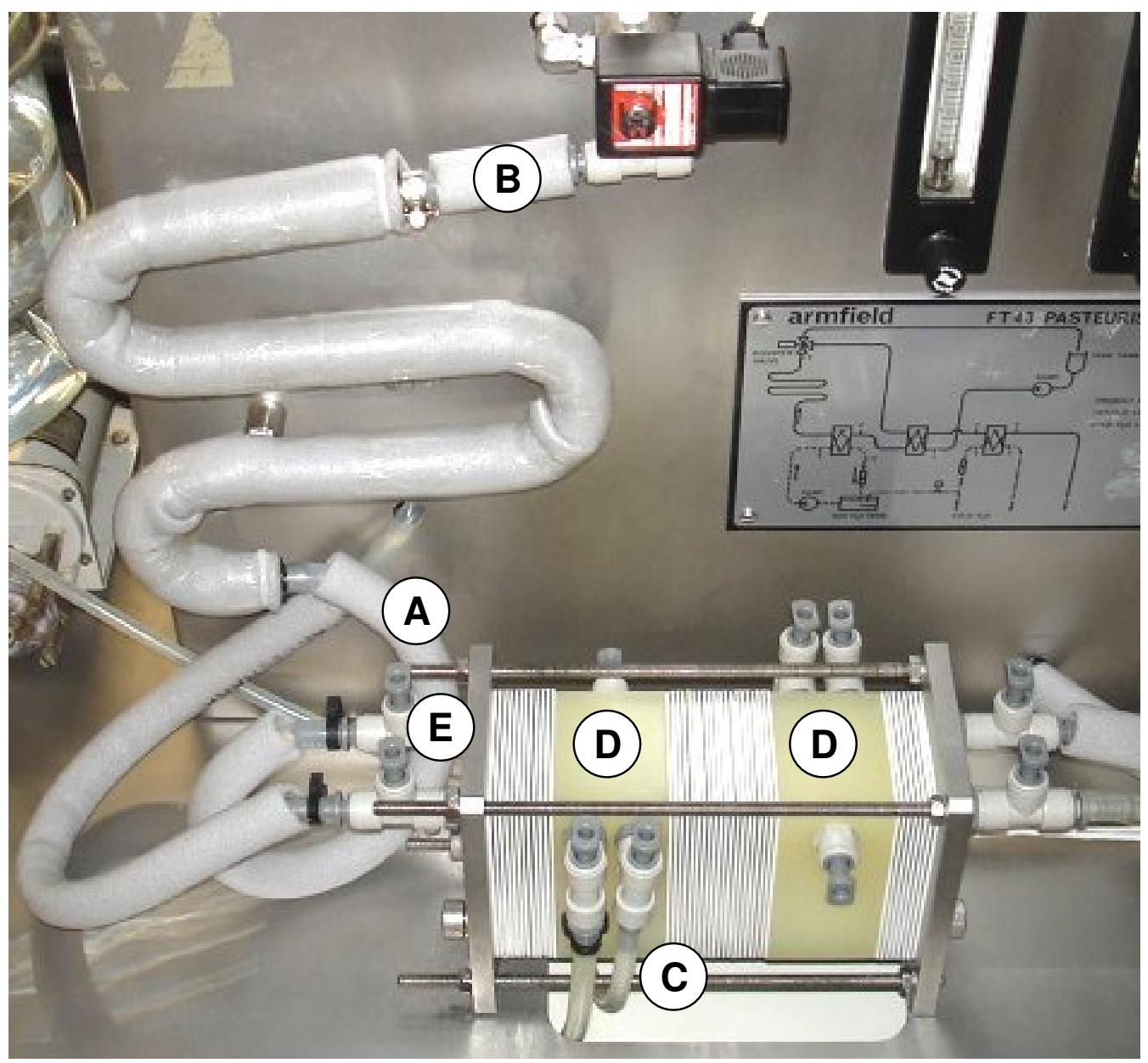

Figura 3-5: Foto do pasteurizador identificando as conexões.

Os pontos estudados foram:

p1 - entrada do produto cru na regeneração;

p2 - entrada do produto no aquecimento;

p3 - saída do produto do aquecimento;

p4 - saída do produto do tubo de retenção;

p5 - entrada do produto na regeneração;

p6 - entrada do produto no resfriamento;

p7 - saída do produto do pasteurizador;

h1, h2 - entrada e saída da água de aquecimento, respectivamente;

c1, c2 - entrada e saída da água de resfriamento, respectivamente. 

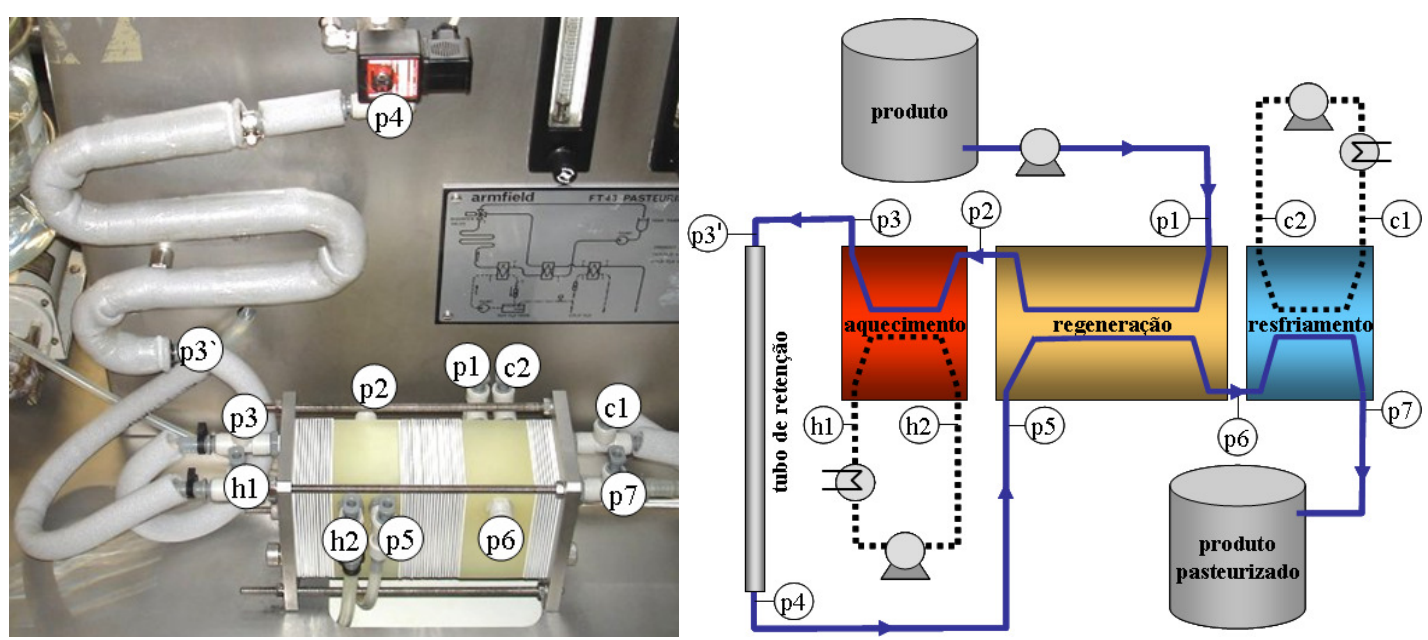

Figura 3-6: Pasteurizador utilizado e esquema do processo indicando pontos de controle.

A vazão foi calibrada para $20 \mathrm{~L} / \mathrm{h}$, medindo-se tempo pelo cronômetro e massa de água, utilizando-se balança com precisão de 0,1 g (METTLER, PB8001-S, USA).

Os dados experimentais foram coletados quando o processo atingiu o regime permanente, o que foi constatado pela invariância nas temperaturas com o tempo. Os valores de temperatura foram registrados durante 3 minutos. Foram calculados a média e o desvio padrão para esses valores.

A correlação de Nusselt-Reynolds-Prandtl utilizada para calcular coeficiente convectivo foi a da eq. (3-37), determinada experimentalmente para o equipamento utilizado com arranjo em série (MIURA; GUT, 2006).

$$
N u=0,0263 \operatorname{Re}^{0,867} \operatorname{Pr}^{1 / 3}
$$

O tempo médio de residência para o tubo de retenção utilizado foi calculado pela eq. (3-38) de Gutierrez (2008), em que $v^{\prime}$ é a vazão volumétrica.

$$
\bar{t}_{\text {tube }}=\frac{63,6}{v^{\prime}}
$$


Para cada seção do trocador de calor, o tempo médio de residência foi calculado pelas eqs. (3-39), em que $V_{p f}$ e $V_{m t}$ são volume plug flow e volume de mistura perfeita, respectivamente (GUTIERREZ, 2008). A soma desses volumes é inferior ao volume interno do trocador, sendo a diferença considerada como volume morto.

$\bar{t}_{m}=\frac{V_{p f}+V_{m t}}{v^{\prime}}$

Sendo que:

$$
\begin{aligned}
& V_{p f}(m L)=0,1144 P^{2}+3,70 P+2,8 \\
& V_{m t}(m L)=-0,0313 P^{2}+2,25 P
\end{aligned}
$$

Para cálculo de tempo de residência nas mangueiras e conexões utilizou-se o tempo espacial, obtido pela eq. (3-35).

Para verificação da consideração de não troca de energia com o ambiente, fez-se o balanço de energia em cada seção do trocador, sendo que o calor cedido pelo lado quente deve se igualar ao calor recebido pelo lado frio, como mostra a eq. (3-40). Para essa verificação, foram calculados os valores de calor para os lados quente e frio pelas equações mostradas na eq. (3-41) e, em seguida, o erro foi calculado pela eq. (3-42). Para aceitar a conservação de energia, o valor de erro deve ser até $10 \%$.

$Q_{\text {hot }}=Q_{\text {cold }}$

$Q_{\text {hot }}=W_{\text {hot }} C p_{\text {hot }}\left(T_{\text {hot, in }}-T_{\text {hot, out }}\right)$

$Q_{\text {cold }}=W_{\text {cold }} C p_{\text {cold }}\left(T_{\text {cold, out }}-T_{\text {cold , in }}\right)$ 


$$
\text { erro }=\frac{Q_{\text {hot }}-Q_{\text {cold }}}{Q_{\text {hot }}}
$$

Para cada ensaio calculou-se a média da temperatura em cada ponto estudado e compararam-se os resultados de simulação dos modelos 1, 2 e 3, para determinação do melhor modelo.

Para validar a semelhança do comportamento térmico entre a água e o leite, realizou-se um experimento utilizando água destilada e em seguida leite em pó da marca Nestlé ${ }^{\circledR}$ (Ninho ${ }^{\circledR}$ Instantâneo Integral), reconstituído em água destilada, com total de sólidos de $13 \%$, nas condições nominais do equipamento para pasteurização de leite: $T_{\text {past }}=72{ }^{\circ} \mathrm{C}$, vazão de $20 \mathrm{~L} / \mathrm{h}$ de produto e vazão das utilidades de aquecimento e resfriamento de 1,0 L/min.

\subsection{Validação experimental da letalidade}

Definido o Modelo para descrever o processo de pasteurização, utilizou-se um indicador enzimático composto por enzima fosfatase alcalina de mucosa intestinal bovina (EC 3.1.3.1, Sigma-Aldrich cód. P7640) em tampão fosfato ( $p H=6,6$ e força $50 \mathrm{mM}$ ) como indicador para validação do modelo (AGUIAR; YAMASHITA; GUT, 2008).

A atividade pôde ser determinada com sistema Reflectoquant ${ }^{\circledR}$ (Merck) com kits de tiras "fosfatase alcalina em leite de 1,0 a 10,0 U/L". Utilizou-se a eq. (3-43) para cálculo de atividade residual $(A R)$, sendo que $A$ é a atividade média do produto ao final do processo e $A_{0}$ a atividade média da solução enzimática antes do processamento.

$$
A R=\frac{A}{A_{0}}
$$


A partir de dados experimentais, foi obtido o modelo que descreve a cinética de inativação da enzima. A atividade enzimática residual pôde então ser calculada pela eq. (3-44) (AGUIAR; YAMASHITA; GUT, 2008), que é um modelo de primeira ordem com duas isoenzimas.

$A R=\alpha\left[\operatorname{alog}\left(\frac{\int_{0}^{\infty} \operatorname{alog}\left(\frac{T_{r e f}-T}{z_{1}}\right) d t}{D_{1, r e f}}\right]+(1-\alpha)\left[\operatorname{alog}\left(\frac{\int_{0}^{\infty} \operatorname{alog}\left(\frac{T_{r e f}-T}{z_{2}}\right) d t}{D_{2, r e f}}\right)\right]\right.$

Os parâmetros dessa equação ajustados para o indicador enzimático são $\alpha=0,62, z_{1}=5,58^{\circ} \mathrm{C}$ e $z_{2}=11,38^{\circ} \mathrm{C}$, assim como os apresentados na Tabela 3-4.

Tabela 3-4: Parâmetros cinéticos do indicador enzimático, nas temperaturas processadas.

\begin{tabular}{lcccc}
\hline & $\mathbf{7 0}{ }^{\circ} \mathbf{C}$ & $\mathbf{7 5}^{\circ} \mathbf{C}$ & $\mathbf{8 0}{ }^{\circ} \mathbf{C}$ & $85^{\circ} \mathbf{C}$ \\
\hline$D_{1}(s)$ & 4542 & 578 & 73 & 9 \\
$D_{2}(s)$ & 42 & 15 & 5,5 & 2,0 \\
\hline
\end{tabular}

Foram realizados experimentos de processamento contínuo com o indicador ALP no pasteurizador laboratorial Armfield, nas temperaturas $70{ }^{\circ} \mathrm{C}, 75^{\circ} \mathrm{C}, 80{ }^{\circ} \mathrm{C}$ e $85^{\circ} \mathrm{C}$, vazão de produto de $20 \mathrm{~L} / \mathrm{h}$ e das utilidades de aquecimento e resfriamento de 1,0 L/min. Os dados de temperatura coletados foram utilizados para calcular a atividade enzimática residual durante todo o processo, utilizando o modelo da eq. (3-44) e os parâmetros da Tabela 3-4. A atividade residual determinada experimentalmente foi comparada com a prevista pela cinética e pelo perfil de temperatura. 


\section{Resultados e Discussão}

\subsection{Avaliação dos modelos e validação térmica}

Primeiramente, os resultados dos três modelos desenvolvidos são comparados com os resultados experimentais. Os valores de temperatura, obtidos experimentalmente, foram utilizados para os cálculos das propriedades físicas médias do produto e das utilidades, eqs. (3-11)-(3-14). Para a simulação dos modelos, as temperaturas médias de entrada do produto e das utilidades de aquecimento e resfriamento foram usadas como especificações. As distribuições de temperatura para os três modelos e os valores experimentais estão na Figura 4-1, que mostra que os três modelos descrevem bem o processo de pasteurização nos pontos estudados (temperaturas correspondentes aos pontos da Figura 3-6). O resultado do Modelo 3 mostra que a hipótese de linearidade, utilizada para o desenvolvimento dos Modelo 1 e Modelo 2, é válida para esse modelo, sendo que apenas na seção de aquecimento foi possível notar a diferença no perfil de temperatura. Os pontos da Figura 4-1 não identificados são pontos que envolvem as conexões do equipamento. Para estes pontos, as temperaturas foram medidas experimentalmente, porém, para a simulação, foram feitas considerações de que as conexões fossem isotérmicas.

Foi realizado o balanço de energia com os dados experimentais para verificação da hipótese de conservação de energia $\left(Q_{\text {hot }}=Q_{\text {cold }}\right)$. Os valores de erros para os balanços de energia são apresentados na Tabela 4-1.

De acordo com os valores de erro calculados, pode-se confirmar a consideração de conservação de energia, ou seja, a energia liberada pelo lado quente é a mesma recebida pelo lado frio, não havendo troca significativa de calor com o ambiente, para a seção de regeneração, pois há bom isolamento entre as grades conectoras de plástico. Para as seções de aquecimento e resfriamento, o erro é maior que $10 \%$, devido a perdas de energia através do pedestal metálico. A 
perda deve ser maior na seção de aquecimento, pois essa seção é a que apresenta maior diferença de temperatura em relação ao ambiente.

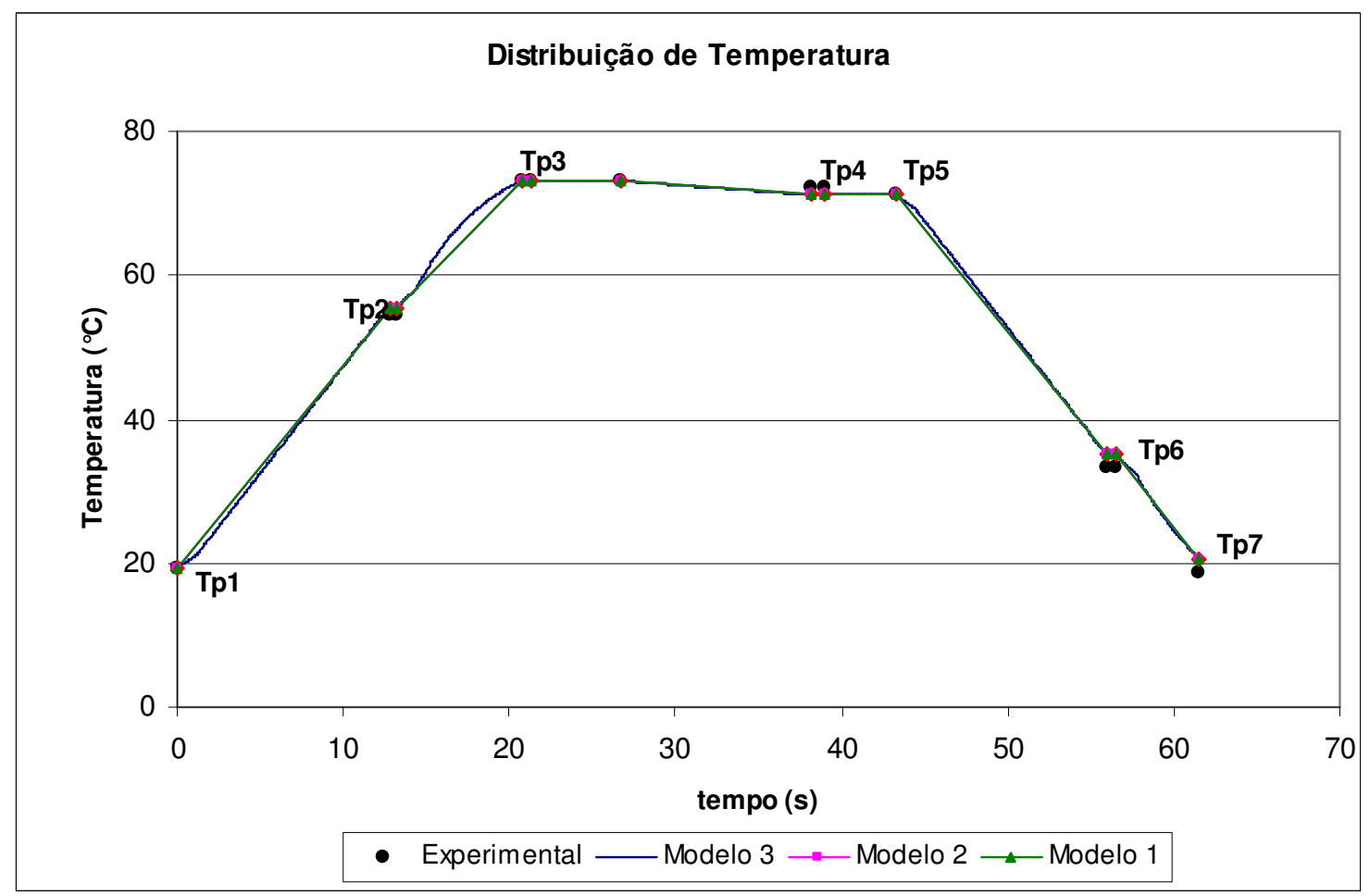

Figura 4-1: Distribuição de temperatura para os três modelos e valores experimentais.

Tabela 4-1: Balanço de energia com valores experimentais para as três seções do pasteurizador.

\begin{tabular}{cccc}
\hline Seção & & {$[W]$} & Erro \\
\hline Aquecimento & $Q_{\text {hot }}$ & 498 & $14 \%$ \\
& $Q_{\text {cold }}$ & 427 & \\
Regeneração & $Q_{\text {hot }}$ & 876 & $6 \%$ \\
& $Q_{\text {cold }}$ & 816 & \\
Resfriamento & $Q_{\text {hot }}$ & 339 & $12 \%$ \\
& $Q_{\text {cold }}$ & 296 & \\
\hline
\end{tabular}


Para avaliação das temperaturas determinadas pelos modelos, foi utilizado o erro quadrático na temperatura, calculado pela eq. (4-1). O Modelo 3 apresenta o menor valor para erro quadrático, como mostrado pela Tabela 4-2. Entretanto, as diferenças entre os modelos são pequenas, como pode ser notado na Figura 4-1. Como o arranjo em série do trocador testado tem vários passes em contracorrente, ele se aproxima de um arranjo contracorrente ideal, fato que justifica a proximidade entre os modelos, o que sugere que a escolha do melhor modelo para descrever o processo seja baseada na simplicidade e robustez do modelo. Dessa forma, escolheu-se 0 Modelo 2, pois apresenta equacionamento mais simples que o Modelo 3, porém leva em conta a configuração do equipamento, não considerada pelo Modelo 1. Considerar a configuração do equipamento é importante nos casos que se afastam do arranjo contracorrente ideal, como por exemplo no arranjo paralelo.

Erro quadrático $=\sum\left(T_{\exp }-T_{\text {cal }}\right)^{2}$

Tabela 4-2: Erro quadrático na determinação das temperaturas $\left({ }^{\circ} \mathrm{C}^{2}\right)$, para cada modelo.

Modelo 1 Modelo 2 Modelo 3

\begin{tabular}{lll}
\hline 12,99 & 12,99 & 12,98 \\
\hline
\end{tabular}

A letalidade integrada é outro importante parâmetro para a escolha do melhor modelo. Na Figura 4-2 são mostradas as curvas de letalidade acumulada e os valores de $F_{72^{\circ} \mathrm{C}}$, tempo de processo, para cada modelo, considerando pasteurização à temperatura de referência de $72{ }^{\circ} \mathrm{C}$. A letalidade acumulada é calculada a partir do histórico tempo-temperatura, tendo em vista a inativação de Coxiella burnetti, com $z=4,4^{\circ} \mathrm{C}$ e utilizando os tempos de residências calculados pelas eqs. (3-38) e (3-39).

Avaliando-se as letalidades para cada modelo na Figura 4-2, observa-se que os valores de $F_{\text {Tref }}$ apresentam pouca diferença entre os modelos, o que pode ser justificado pela semelhança entre as distribuições de temperatura geradas por eles. 
Assim, o Modelo 2 escolhido anteriormente continua sendo o melhor para descrição do processo.
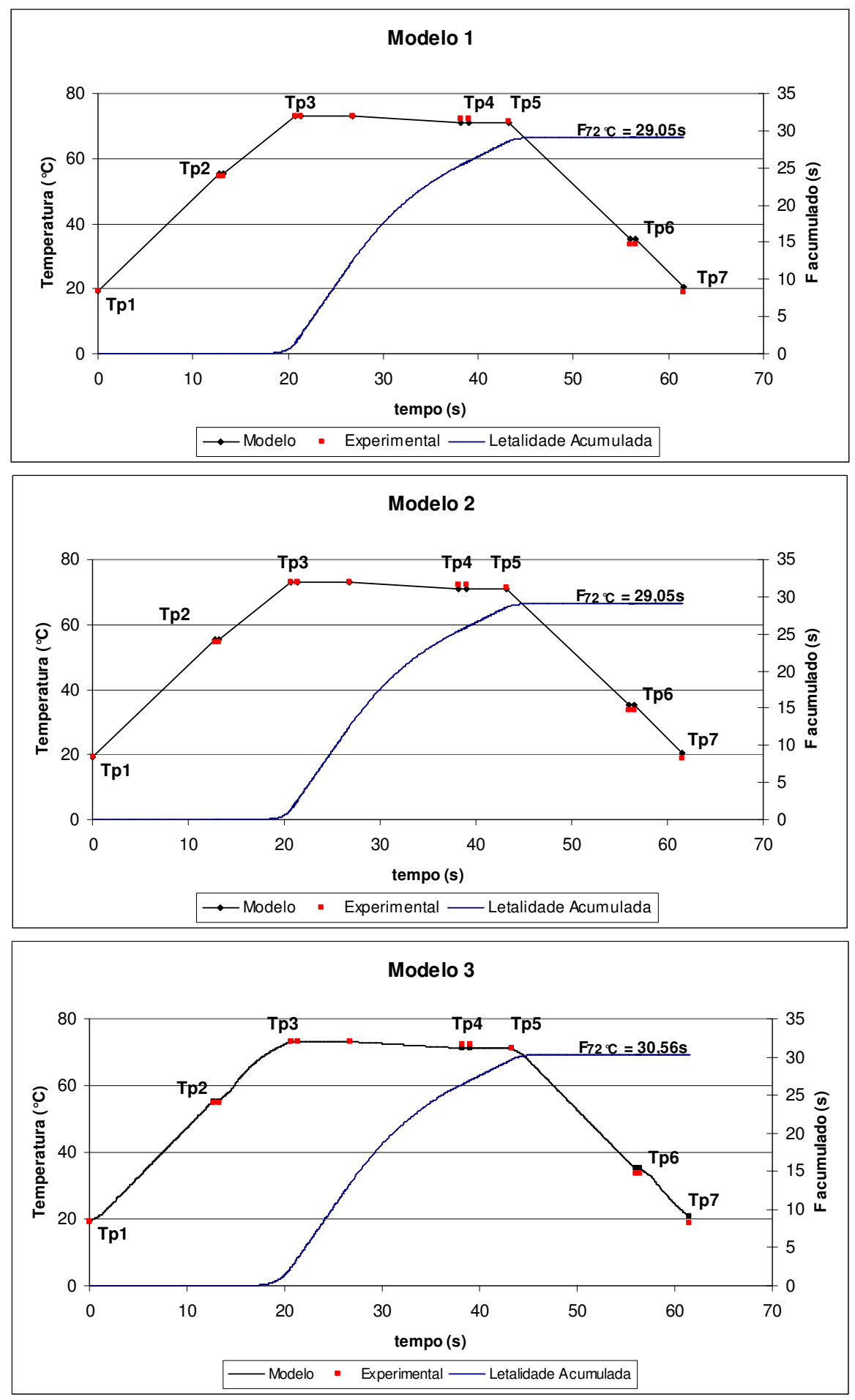

Figura 4-2: Distribuição de temperatura e a letalidade acumulada para os três modelos. 
A Figura 4-3 mostra a distribuição de temperatura experimental no pasteurizador, assim como a letalidade experimental para a pasteurização de leite no equipamento testado. $O$ valor de $F_{\text {Tref }}$ experimental, $F_{72^{\circ} \mathrm{C} \text { exp }}=32,05 \mathrm{~s}$, é maior que o dobro do tempo de processo ideal, $F_{72^{\circ} \mathrm{C} \text {,ideal }}=15 \mathrm{~s}$, que é atigindo antes da metade do tubo de retenção. O processo está superdimensionado e o produto, dessa forma, sobreprocessado.

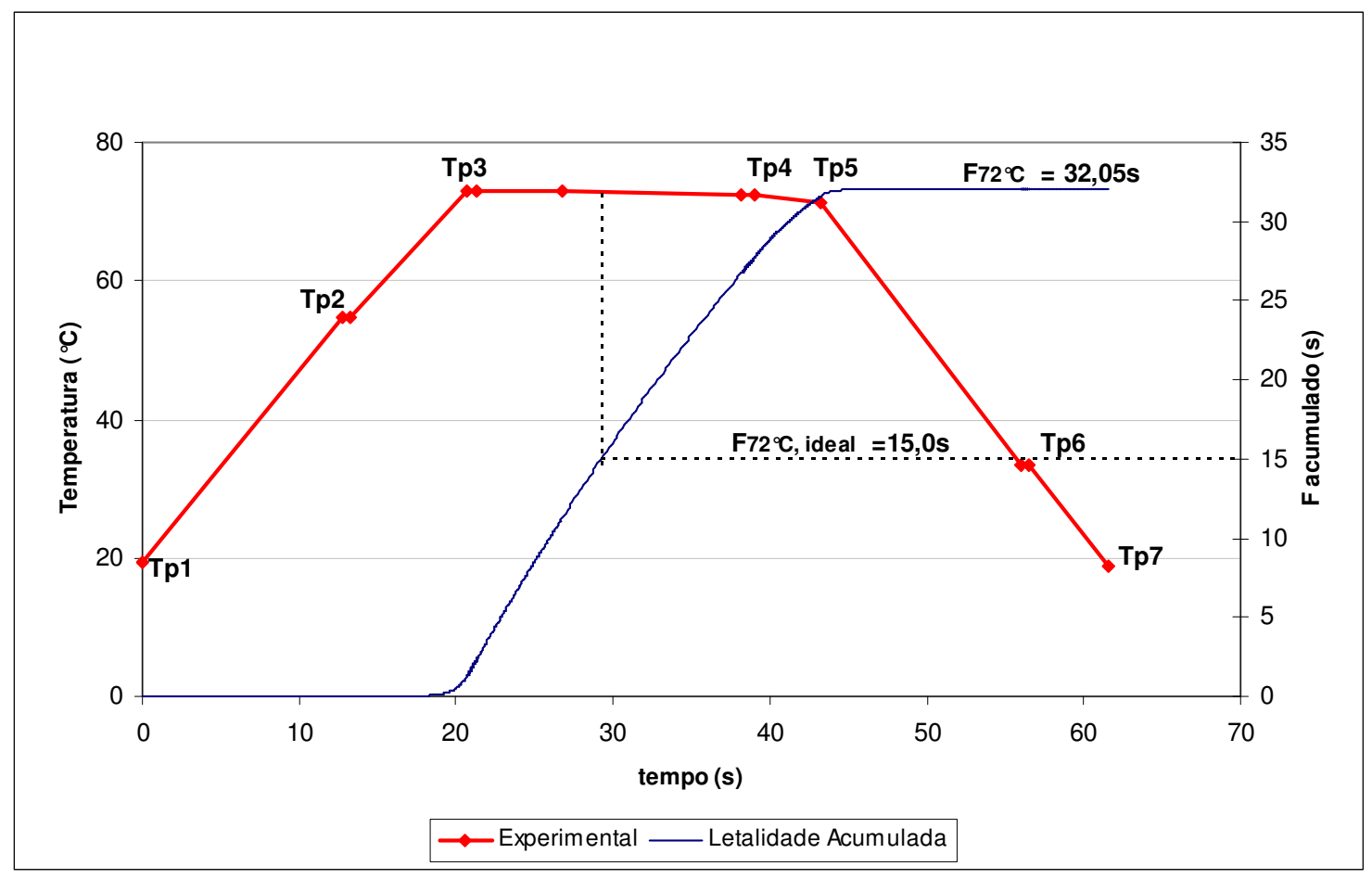

Figura 4-3: Distribuição de temperatura e letalidade acumulada para os dados experimentais.

Pode-se perceber que as etapas de aquecimento e resfriamento regenerativo, assim como o escoamento nas conexões antes e depois do tubo de retenção, contribuem significativamente para a letalidade real, sendo que $51 \%$ da letalidade ocorre fora do tubo de retenção. A perda de calor no escoamento pelo tubo também eleva muito a letalidade, ocasionando o sobreprocessamento. A temperatura de saída do aquecimento é $T_{p 3}=75^{\circ} \mathrm{C}$. 


\subsection{Validação experimental da letalidade}

As curvas da Figura 4-4 mostram a atividade residual da enzima ao longo dos processamentos contínuos, nas temperaturas nominais de pasteurização $70{ }^{\circ} \mathrm{C}, 75$ ${ }^{\circ} \mathrm{C}, 80{ }^{\circ} \mathrm{C}$ e $85^{\circ} \mathrm{C}$.
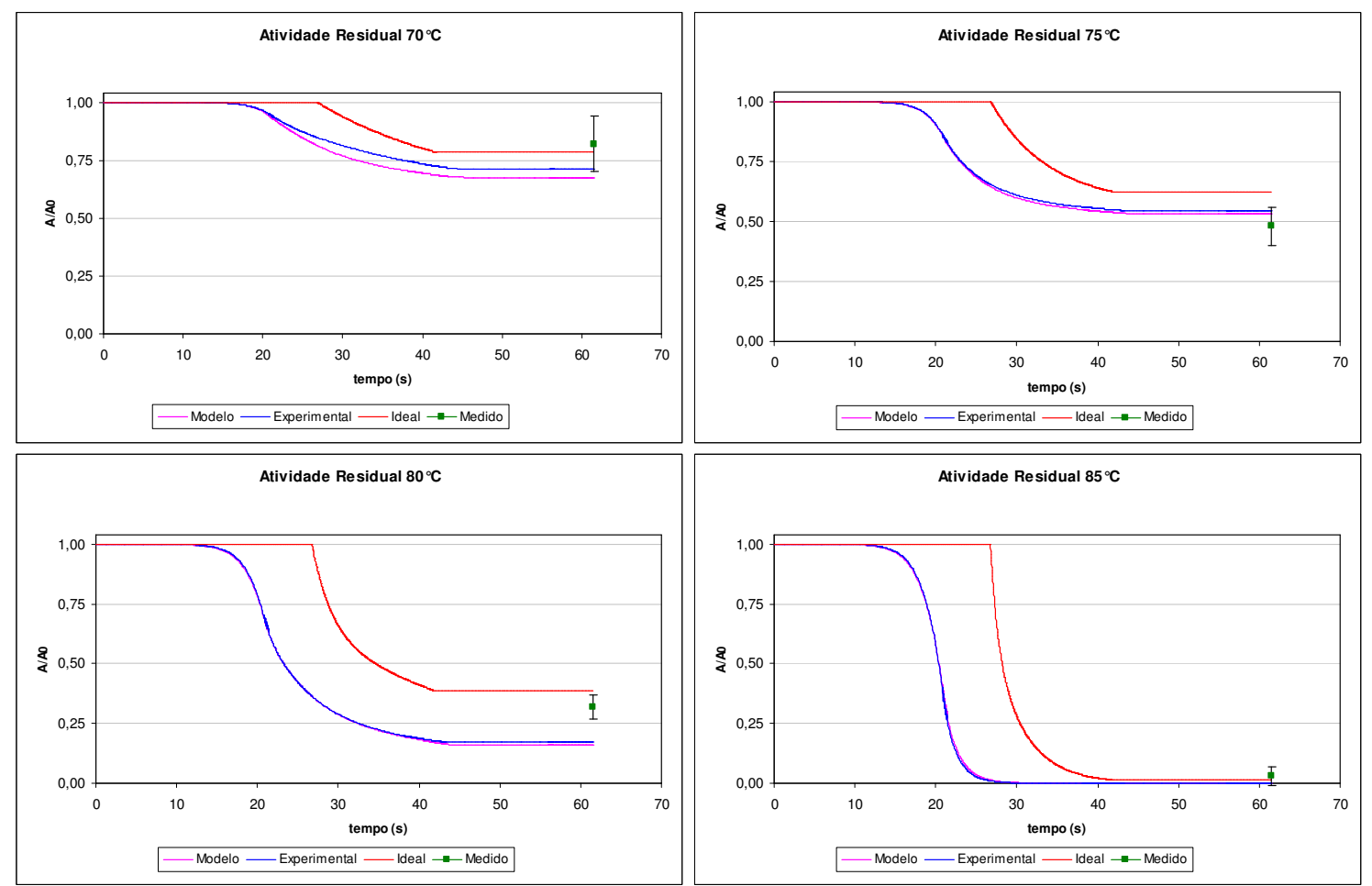

Figura 4-4: Comparação das curvas de atividade residual calculadas pelo Modelo 2 e com os valores experimentais, curva ideal para pasteurização e o valor medido com produto no final do processo, nas temperaturas de $70{ }^{\circ} \mathrm{C}, 75^{\circ} \mathrm{C}, 80^{\circ} \mathrm{C}$ e $85^{\circ} \mathrm{C}$.

As curvas "Experimental" e "Modelo" foram calculadas a partir dos históricos de temperatura experimental e simulado com o Modelo 2, respectivamente.

A curva "Ideal" foi calculada levando em conta que a temperatura da solução enzimática varia instantaneamente para a temperatura de pasteurização na entrada do tubo de retenção e se mantém constante até a saída do tubo e depois cai novamente de forma instantânea para a temperatura de saída do processo. A curva ideal deve apresentar valor para atividade enzimática residual maior que os valores experimental e do modelo, como ocorreu em todas as temperaturas estudadas. 
Os pontos "Medido" indicam atividade residual média medida na saída do processo e foram obtidos conforme procedimento experimental. Com relação à temperatura, a atividade enzimática residual deve decrescer com o aumento da temperatura, como pode ser notado na Figura 4-4. Os valores medidos são apresentados na Tabela 4-3, assim como os valores calculados para atividade residual, obtidos pela eq. (3-43).

Tabela 4-3: Valores medidos de atividade enzimática $(A)$ e atividade residual $(A R)$ e seus desvios padrões, para as temperaturas estudadas.

\begin{tabular}{ccc}
\hline$T\left({ }^{\circ} C\right)$ & $A(U / L)$ & $A R$ \\
\hline$T_{a m b}\left(A_{0}\right)$ & $11,10 \pm 1,22$ & - \\
70 & $9,14 \pm 0,93$ & $0,82 \pm 0,12$ \\
75 & $5,30 \pm 0,64$ & $0,48 \pm 0,08$ \\
80 & $3,50 \pm 0,39$ & $0,32 \pm 0,05$ \\
85 & $0,34 \pm 0,47$ & $0,03 \pm 0,04$ \\
\hline
\end{tabular}

Para todas as temperaturas de pasteurização as curvas de letalidade experimental e do modelo se comportam de forma semelhante e seus valores para atividade residual no final do processo são muito próximos.

Os valores experimentais estão contidos no intervalo dos valores de $A R$ apresentados na Tabela 4-3. Devido ao considerável erro experimental, esse método não apresentou precisão adequada para quantificar a letalidade do processo. Apesar do erro na determinação do valor experimental, o valor calculado pelo modelo está contido no intervalo de desvios padrão, comprovando seu uso como integrador tempo-temperatura. Porém, é necessário buscar outro método que quantifique com maior precisão ou reduzir o erro deste.

Assim, o modelo cinético para determinação de atividade residual da fosfatase alcalina, mostrada na eq. (3-44), pode ser utlizado na simulação do processo de pasteurização utilizando trocador de calor a placas. 


\subsection{Ensaio com leite}

Como observado pela Figura 4-5, o leite se comportou termicamente como a água durante o processo de pasteurização no trocador de calor a placas, como esperado, pois ambos são fluidos newtonianos e possuem semelhanças entre suas propriedades físicas como calor específico, viscosidade e densidade. Portanto, foi adequado o uso da água para estudo da troca térmica no processo, comprovando que as conclusões obtidas neste trabalho pelos experimentos com água são válidas para o processamento de leite.

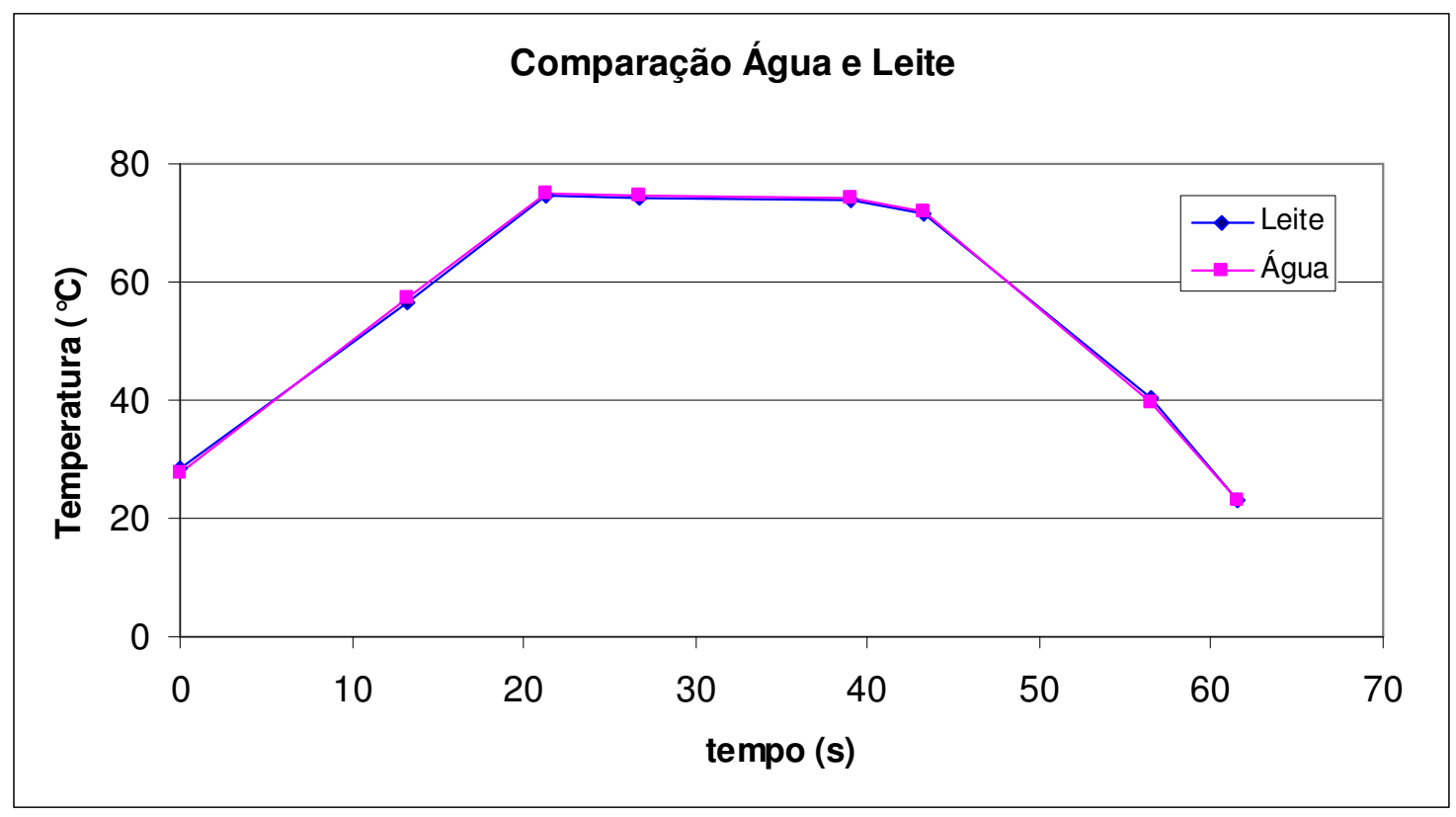

Figura 4-5: Dados de temperatura para processamento contínuo de água destilada e leite integral com $13 \%$ de sólidos totais, com temperatura de pasteurização de $72{ }^{\circ} \mathrm{C}$. 


\section{Conclusões}

A partir da proposta de trabalho, foi possível desenvolver uma modelagem matemática para determinação do histórico tempo-temperatura do processo de pasteurização contínua HTST de leite, utilizando trocador de calor a placas.

Para os três modelos desenvolvidos, os valores de temperatura calculados nos pontos estudados apresentaram pequena diferença em relação aos valores experimentais, sendo que o Modelo 3 apresentou menor valor para erro quadrático na determinação das temperaturas.

A letalidade integrada calculada para os dados experimentais mostrou que 0 processo estudado está superdimensionado e, dessa forma, o produto sobreprocessado, pois seu valor ultrapassa o dobro do tempo de processo ideal de 15 segundos para pasteurização HTST. Os valores para letalidade integrada calculados pelos modelos desenvolvidos ficaram abaixo do valor experimental, porém maiores que o valor ideal, sendo que o Modelo 3 apresentou valor mais coerente com o experimental.

Apesar do Modelo 3 apresentar menor valor para erro quadrático na determinação das temperaturas e valor para letalidade integrada mais próxima ao experimental, a diferença entre todos os modelos é muito pequena, o que sugere que a escolha do melhor modelo para descrever o processo seja baseada na simplicidade e robustez do modelo. Dessa forma, escolheu-se o Modelo 2, pois apresenta equacionamento simples, porém leva em conta a configuração do equipamento.

O modelo para determinação da atividade residual da enzima fosfatase alcalina em tampão fosfatase descreve bem a redução da atividade durante o processo de pasteurização no trocador de calor a placas utilizado, o que foi comprovado processando solução enzimática e medindo atividade residual ao final do processo. Apesar do erro na determinação do valor experimental, o valor calculado pelo modelo está contido no intervalo de desvios padrão, comprovando o uso dessa solução como integrador tempo-temperatura. Dessa forma, esse modelo cinético pode ser usado para cálculo de atividade residual na simulação do processo. 
O experimento utilizando leite em pó reconstituído, mostrou que é adequado o uso de água para estudo da troca térmica no processo, visto que ambos são fluidos newtonianos e possuem semelhanças entre suas propriedade físicas, como calor específico, viscosidade e densidade, assim, validando todo o desenvolvimento deste trabalho. 


\section{Perspectivas para Trabalhos Futuros}

Algumas sugestões para continuação desta linha de pesquisa:

- Utilizar o modelo em problemas de otimização para reduzir custos e melhorar qualidade do produto.

- Ampliar o modelo para representar o estado não estacionário de operação.

- Acrescentar no modelo transiente a cinética de incrustação.

- Testar e validar o modelo com configurações diferentes, que se afastam da configuração contracorrente ideal.

- Utilizar um modelo que descreva a variação de temperatura no tubo de retenção e nas conexões.

- Buscar outro método que quantifique com maior precisão a atividade residual da enzima fosfatase alcalina ou reduzir o erro do método utilizado. 


\section{REFERÊNCIAS BIBLIOGRÁFICAS ${ }^{2}$}

AGUIAR, H. F.; YAMASHITA, A. S.; GUT, J. A. W. Estudo de indicadores enzimáticos de determinação rápida para avaliação da pasteurização contínua. p. 13 In: XXI Congresso Brasileiro de Ciência e Tecnologia de Alimentos, 2008, Belo Horizonte. XXI CBCTA, 2008.

AHVENAINEN, R. New Approaches in Improving the Shelf Life of Minimally Processed Fruit and Vegetables. Review. Trends in Food Science \& Technology, v. 7, p. 179-187, 1996.

ANGElinO, P. D.; CHIRSTEN, G. L.; PENFIELD, M. P.; BEATTIE, S. Residual Alkaline Phosphatase Activity in Pasteurized Milk Heated at Various Temperatures Measurements with the Fluorophos and Scharer Rapid Phosphatase Tests. Journal of Food Protection. v. 62, n. 1, p. 81-85, 1999.

BRASIL. ANVISA - Agência Nacional de Vigilância Sanitária. Aprova o novo Regulamento da Inspeção Industrial e Sanitária de Produtos de Origem Animal. Decreto nº 30691, de 29 de março de 1952. D.O.U. - Diário Oficial da União; Poder Executivo, de 07 de julho de 1952. Disponível em:

<http://e-legis.anvisa.gov.br/leisref/public/showAct.php?id=18\&word=Aprova o novo Regulamento da Inspe\%C3\%A7\%C3\%A3o Industrial e Sanit\%C3\%A1ria de Produtos de Origem Animal> Acesso em 16 out. 2008.

CERF, O.; CONDRON, R. Coxiella burnetti and Milk Pasteurization: An Early Application of the Precautionary Principle? Epidemiology \& Infection. v. 134, n. 5, p. 946-951, 2006.

CHENG, H.; FRIIS, A. Operability and Flexibility of Milk Production Line. Food and Bioproducts Processing, v. 85, n. C4, p. 372-380, 2007.

\footnotetext{
${ }^{2}$ Baseado na Norma ABNT NBR 6023 (2002) com as devidas adaptações à literatura da área da engenharia.
} 
CHOI, Y.; OKOS, M. R. Thermal Properties of Liquid Foods - Review, In: OKOS, M. R. (Ed.). Physical and Chemical Properties of Food. St. Joseph: ASAE, 1986. p. 3577.

DYMOND, G. Pasteurization of Beer in Plate Heat Exchangers: Lower Costs and Higher Quality. Cerevisia, v. 22, n. 4, p. 37-48, 1997.

FOX, P. F.; McSWEENEY, P. L. H. Dairy Chemistry and Biochemistry. 1. ed. London: Blackie Academic \& Professional, 1998. p. 324-327.

GENTRY, T. S.; ROBERTS, J. S. Formation Kinetics and Application of 5hydroxymethylfurfural as a Time-Temperature Indicator of Lethality for Continuous Pasteurization of Apple Cider. Innovative Food Science and Emerging Technologies, v. 5, n. 2, p. 327-333, 2004.

GRIJSPEERDT, K.; HAZARIKA, B.; VUCINIC, D. Application of Computational Fluid Dynamics to Model the Hydrodynamics of Plate Heat Exchangers for Milk Processing. Journal of Food Engineering, v. 57, p. 237-242, 2003.

GRIJSPEERDT, K.; MORTIER, L.; de BLOCK, J.; van RENTERGHEM, R. Application of Modeling to Optimize Ultra High Temperature Milk Heat Exchangers with Respect to Fouling. Food Control, v. 15, p. 117-130, 2004.

GUT, J. A. W. Configurações Ótimas para Trocadores de Calor a Placas. 2003. 244p. Tese (Doutorado) - Escola Politécnica, Universidade de São Paulo, São Paulo, 2003.

GUT, J. A. W.; FERNANDES, R.; TADINI, C. C.; PINTO, J. M. HTST Milk Processing: Evaluating the Thermal Lethality inside Plate Heat Exchangers. In: International Congress on Engineering and Food iCEF 9, 2004, Montpellier. Proceedings of iCEF 9, 2004. 
GUT, J. A. W.; PINTO, J. M. Modeling of Plate Heat Exchangers with Generalized Configurations. International Journal of Heat and Mass Transfer, v. 46, n. 14, p. 2571-2585, 2003.

GUT, J. A. W.; PINTO, J. M. Optimal design of continuous thermal processing with plate heat exchangers. In: Erdogdu, F. (Org.). Optimization in Food Engineering. Boca Raton: CRC Press, 2009. v. 1, p. 597-631, 2009.

GUT, J. A. W.; PINTO, J. M.; GABAS, A. L.; TELIS-ROMERO, J. Continuous Pasteurization of Egg Yolk: Thermophysical Properties and Process Simulation. Journal of Food Process Engineering, v. 28, p. 181-203, 2005.

GUtierReZ, C. G. C. C. Distribuição do Tempo de Residência em Processo de Pasteurização com Trocador de Calor a Placas. 2008. 98p. Dissertação (Mestrado) Escola Politécnica, Universidade de São Paulo, São Paulo, 2008.

JUNG, A.; FRYER, P. J. Optimizing the Quality of Safe Food: Computational Modeling of a Continuous Sterilization Process. Chemical Engineering Science, v. 54, n. 6, p. 717-730, 1999.

KAKAÇ, S.; LIU, H. Heat Exchangers: Selection, Rating and Thermal Design. 2. ed. Boca Raton: CRC Press, 2002. 501 p.

LADO, B. H.; YOUSSEF, A. E. Alternative Food-Preservation Technologies: Efficacy and Mechanisms. Microbes and Infections, v. 4, n. 4, p. 433-440, 2002.

LANDFELD, A.; ZITNÝ, R.; HOUSKA, M.; KÝHOS, K.; NOVOTNÁ, P. Residence Time Distribution during Egg Yolk Pasteurization. Czech Journal of Food Science, v. 20, n. 5, p. 193-201, 2002.

LEVENSPIEL, O. Engenharia das Reações Químicas. Tradução de Verônica M. A. Calado. Revisão técnica Frederico W. Tavares. 3. ed. São Paulo: Editora Edgard Blücher, 2007. 563p. 
LEWIS, M. J. Thermal Processing. In: Brennan, J. G. (Ed.). Food Processing Handbook. Weinheim: WILEY-VCH Verlag GmbH \& Co. KGaA, 2006. p. 33-70.

LEWIS, M.; HEPPELL, N. Continuous Thermal Processing of Foods: Pasteurization and UHT Sterilization. Gaithersburg: Aspen Publishers, 2000. 447 p.

MARTH, E. H.; STEELE, J. L. Applied Dairy Microbiology. 2. ed. New York: Marcel Dekker, 2001. 744 p.

MIURA, R. Y.; J. A. W. GUT. Estudo da Troca Térmica em um Trocador de Calor a Placas com Configurações Generalizadas. São Paulo: FAPESP, 2006. (Relatório de iniciação científica).

RICHARDSON, P. S. Thermal Technology in Food Processing. Boca Raton: CRC Press, 2001. $294 \mathrm{p}$.

TOLEDO, R. T. Fundamentals of Food Process Engineering. 2. ed. New York: Chapman \& Hall, 1999. 579 p.

TORTORA, G. J.; FUNKE B. R.; CASE C. L. Microbiologia. Traduzido e atualizado por Roberta Marchiori Martins. 8. ed. Porto Alegre: Artmed, 2005. 894 p.

TRIBESS, T. B.; TADINI, C. C. Inactivation Kinetics of Pectin Methylesterase in Orange Juice as a Function of $\mathrm{pH}$ and Temperature/Time Process Conditions. Journal of the Science of Food and Agriculture, v. 86, n. 9, p. 1328-1335, 2006.

USA. FDA U.S. Food and Drug Administration. Grade "A" Pasteurized Milk Ordinance (2003 Revision). Disponível em: <http://www.cfsan.fda.gov/ ear/pmo03toc.html> Acessado em 21 out. 2008.

WALSTRA, P.; GEURTS, T. J.; JELLEMA, A.; NOOMEN, A.; van BOEKEL M. A. J. S. Dairy Technology: Principles of Milk Properties and Processes. New York: Marcel Dekker, 1999. 727 p. 